\title{
Is the GATT/WTO's Article XXIV Bad?*
}

\author{
Monika Mrázovátł \\ University of Surrey; \\ and CEP, LSE
}

\author{
David Vines ${ }^{\S}$ \\ University of Oxford; \\ Australian National University; \\ and CEPR
}

July 25, 2012

\section{Ben Zissimos}

University of Exeter

\begin{abstract}
The GATT/WTO Article XXIV prevents a customs union (CU) from raising its common external tariff. In this paper, we compare CU formation with and without this Article XXIV constraint. We show, in a multi-country oligopoly model, that for a given CU structure, Article XXIV improves world welfare by lowering trade barriers. However, we also show that Article XXIV has a composition effect on CU formation: it affects the endogenous choice of CUs. By encouraging more symmetric CUs, Article XXIV causes more trade to be subject to trade barriers. As a result, Article XXIV may be 'bad' for world welfare.
\end{abstract}

KEYWORDS: Coalition formation game, customs union, protection, trade block, trade liberalization.

JeL Classification Numbers: F02, F13, F15.

${ }^{*}$ We are very grateful to Rick Bond, Peter Neary and Emanuel Ornelas for extensive conversations about this paper. We would also like to thank Régis Cottereau, Antoine Thibault, Nick Trefethen, and participants in seminars at Michigan State University, the University of Oxford, Vanderbilt University, and the 50th Midwest International Trade Meeting at Purdue University for helpful comments. We are particularly indebted to the editor, Robert W. Staiger, and two anonymous referees for extremely helpful suggestions.

${ }^{\dagger}$ Corresponding author: School of Economics, University of Surrey, Guildford, Surrey, GU2 7XH, United Kingdom; e-mail: m.mrazova@surrey.ac.uk; URL: http://www.monikamrazova.com

¥This work has been supported by the Economic and Social Research Council [grant numbers PTA-02627-2479, PTA-030-2005-00825]. Financial support for travel from the George Webb Medley Fund, Balliol College and Oriel College, Oxford, is also gratefully acknowledged.

$\S$ E-mail: david.vines@economics.ox.ac.uk

『E-mail: b.zissimos@exeter.ac.uk 


\section{Introduction}

Article XXIV of the General Agreement on Tariffs and Trade (GATT), as incorporated into the World Trade Organization (WTO), allows WTO-member governments to form customs unions (CUs) or free trade agreements (FTAs) under two conditions: First, members should eliminate (substantially) all internal barriers to trade inside the union; second, external trade barriers should not be increased on average. ${ }^{1,2,3}$ Intuition might suggest that, compared to a world where bloc formation is allowed without any constraints, Article XXIV must increase world welfare, since it precludes (average) tariff increases on non-members by countries that form preferential trade agreements while requiring tariff removal between members. Yet, there has been considerable debate in policy circles as to whether Article XXIV is in fact so benign. In our paper, which is among a small but growing number of papers to analyze the implications of Article XXIV formally, we show that the simple intuition outlined above ignores the effect that Article XXIV has on the manner in which countries endogenously organize themselves into trade blocs. We will refer to this as the 'composition effect' of Article XXIV. By taking account of this composition effect of bloc formation we are able to show that Article XXIV may actually be bad for world welfare.

To analyze Article XXIV, we focus on CU formation and adopt as a benchmark the model of Yi (1996). ${ }^{4}$ This model is the simplest framework where we can identify the composition effect of Article XXIV. It has two key features. First, there can be any number (greater than or equal to three) of countries in the model. And second, the number of CUs and the country membership of each are determined endogenously through a coalition formation game: governments decide on CU membership to maximize their country's welfare.

In this paper, we formally introduce into the benchmark model an 'Article XXIV constraint,' that trade barriers cannot be raised on average when a CU forms or expands. This is a formalization of the second condition of Article XXIV introduced above. (The first condition that all internal barriers be removed is already a feature of our benchmark model.) This constraint has been considered in previous literature, but not, to our knowledge, in a many-country model with endogenous CU formation. Indeed, most previous research on

\footnotetext{
${ }^{1}$ Article XXIV was originally formulated as part of the General Agreement on Tariffs and Trade (GATT), and has now been formally adopted into the Charter of the WTO (GATT 1994). The historical events through which Article XXIV came into being are discussed by Snape (1993) and Irwin et al. (2008). Its implementation in practice is documented by McMillan (1993).

${ }^{2} \mathrm{~A}$ third condition of Article XXIV, which will not have a bearing on our analysis, is that all agreements must be notified to the WTO.

${ }^{3}$ The common feature of CUs and FTAs is that both types of agreement coordinate on the removal of internal tariffs; the difference is that CUs coordinate on the setting of a common external tariff whereas each member of an FTA undertakes external tariff setting independently.

${ }^{4}$ In studying Article XXIV, our focus on CUs seems legitimate since CU members internalize any termsof-trade externality between themselves through coordination and thus tend to set higher tariffs than FTAs. Indeed, Bond et al. (2004) and Ornelas (2005a) have shown, in different settings, that FTAs tend to compete external tariffs down through their bids for third markets, in which case the Article XXIV constraint would not bind.
} 
CU formation is carried out on a 'standard model' in which there are just three countries and $\mathrm{CU}$ formation is imposed exogenously on two of the countries with the third remaining outside to capture the effects of $\mathrm{CU}$ formation on a non-member. Therefore, the composition effect of Article XXIV that we identify has not been observed.

To reveal the importance of the composition effect of Article XXIV, we first study the effects of Article XXIV ignoring the composition effect. That is, we treat CU membership as exogenously given and we show that Article XXIV increases world welfare. Thus, if we ignore the composition effect, the simple intuition outlined above does hold. Then, we allow countries to endogenously form CUs both with and without the Article XXIV constraint. We show that Article XXIV affects the incentives of countries to form CUs and changes the equilibrium $\mathrm{CU}$ structure such that world welfare may be lower with Article XXIV than without Article XXIV.

In our benchmark model, each country has a single firm that produces a (single) different variety of a (horizontally differentiated) product, and firms compete internationally for a segment of each other's market. The substitutability between varieties varies from one end of the spectrum where each variety enters preferences 'independently' to the other end where varieties are perfect substitutes for another. Governments set a tariff on imports to maximize welfare of their country. When allowed to form CUs, governments choose the size of the CU and set a common external tariff (CET) to maximize joint welfare of all members. The CET varies with the size of the $\mathrm{CU}$ and with the substitutability between goods. As a CU becomes larger, it wants to exploit its bigger market power by raising its CET. On the other hand, the removal of internal barriers in the CU diverts trade away from the rest of the world towards CU members. As consumers prefer more variety, this trade-diversion effect tends to decrease the CET. When goods are independent, CU expansion does not divert trade much, the market-power effect dominates and the CET increases with the size of the union. The Article XXIV constraint is thus more binding on large CUs. When goods are more substitutable, the trade-diversion effect starts to dominate when the CU reaches a certain critical size and a sufficiently large CU imposes a lower CET than a smaller CU. And so the Article XXIV constraint is more binding on small CUs.

Considering exogenous CU formation, we show that Article XXIV positively affects some of the welfare effects of $\mathrm{CU}$ formation. Non-members are made less worse off by $\mathrm{CU}$ formation under Article XXIV than without it, consumer surplus of members unambiguously increases, and for a given CU structure, the Article XXIV constraint increases world welfare. We also show that, under Article XXIV, an (exogenous) increase in the asymmetry of the CU structure increases world welfare. More asymmetry between the blocs implies a larger number of goods are traded within the larger bloc and so a smaller number of goods are subject to welfare-reducing tariff distortions (the most extreme possible asymmetry is world welfare maximizing free trade).

Then we analyze the effects of Article XXIV on the (endogenously-formed) CU equi- 
librium. For a given number of countries in the world, equilibrium CU structure depends on the substitutability between varieties. When goods are independent, the gains from free trade outweigh the gains from market-power exploitation through tariffs and so the equilibrium CU structure is one single bloc, which is of course equivalent to world free trade. Put differently, when goods are independent, outsiders can inflict a large welfare loss on any $\mathrm{CU}$ and so all countries agree to form one single bloc. When goods are more substitutable, countries that start the CU formation process are better off if they leave some other countries outside their bloc and are thereby able to exploit their market power over them. We show that there will typically be two asymmetric CUs in equilibrium. The size of these CUs decreases with the order of formation: the first bloc to form is larger as members of larger blocs have larger welfare.

Article XXIV affects the size of these equilibrium CUs. It has two effects working in opposite directions depending on whether it binds on the larger first-formed bloc or the smaller second-formed bloc. When the first bloc is constrained by Article XXIV, it would want to accept more members, because Article XXIV sets a bound on foreign rent extraction and thus makes the benefits from freer trade relatively larger. On the other hand, when the second bloc is constrained by Article XXIV, the first bloc would want to accept fewer members because the welfare loss that the second bloc can inflict on the first bloc is smaller. Which of these two effects dominates depends on which bloc is more constrained by Article XXIV, which in turn depends on the substitutability between goods. For independent goods, the larger first bloc is more constrained and so the composition effect of Article XXIV tends to make the equilibrium CU structure more asymmetric. A corollary of this is that free trade arises for a larger range of substitution elasticities. By increasing the asymmetry between the blocs, Article XXIV is good for world welfare. When goods are relatively substitutable, the smaller second bloc is more constrained and so the composition effect of Article XXIV tends to make the equilibrium CU structure less asymmetric. By reducing the asymmetry between the blocs through its composition effect, Article XXIV may be bad for world welfare, because more goods are traded between the blocs and subject to welfare-reducing tariff distortions. ${ }^{5}$

The most comprehensive previous analysis of Article XXIV is by Syropoulos (1999), using the standard model of $\mathrm{CU}$ formation. He shows that $\mathrm{CU}$ formation can damage the rest of the world even under Article XXIV. But he does not compute the effects of CU formation on world welfare - either with or without Article XXIV. ${ }^{6}$ Furthermore, since Syropoulos' analysis is carried out in a three-country model, the composition effect of Article XXIV, which is crucial to our claim that world welfare may be lower under Article XXIV, cannot

\footnotetext{
${ }^{5}$ Another interpretation of the composition effect is that, when blocs are less asymmetric, there are fewer 'rich countries' and more 'poor countries' in the world since members of the larger bloc have higher welfare than members of the smaller bloc.

${ }^{6}$ Indeed, the standard basis for criticism of Article XXIV is that it is not sufficient to prevent third countries being harmed when two countries form a trade agreement. As far as we are aware, ours is the first paper to evaluate Article XXIV from the perspective of its implications for world welfare.
} 
be discussed in his framework. On the other hand, Goto and Hamada (1999) study Article XXIV in a many-country model, but because they consider exogenous CU formation only, the composition effect, that we identify, cannot be observed in their framework either. ${ }^{7}$

Overall, the literature on preferential trade agreements has addressed two issues. The first of these issues, which was the focus of Viner (1950), Krugman (1991), Syropoulos (1999) etc., concerns the welfare implications of trade agreements in which the structure of the agreement is taken to be exogenous. The second issue is the stability of trade-agreement structures. Given endogenous trade-agreement formation, what structures are stable? Is the process of trade-agreement formation one which will, or will not, lead to free trade? (See Bhagwati (1993), although the roots of this question are found in Viner (1950).) Recent literature has focused on the interaction between these issues: on the welfare implications of stable structures. The present paper is a contribution to this work. It examines the impact of Article XXIV on the stable structures and on the resulting welfare outcomes. ${ }^{8}$

The paper proceeds as follows. In Section 2 we formally introduce the Article XXIV constraint into the benchmark model. We then turn to analyzing the effects of Article XXIV on CU formation and on welfare of CU members, non-members and the entire world. Our analysis proceeds in three steps. Sections 3 and 4 both analyze exogenous CU formation. In Section 3 we look at the effects of a formation or expansion of a particular CU without any information on the CU structure of the rest of the world. In Section 4 we establish the link between welfare and CU structures and study how exogenous changes in CU structures and the imposition of Article XXIV affect welfare. Finally, Section 5 analyses endogenous $\mathrm{CU}$ formation. In this section, we determine stable $\mathrm{CU}$ structures and characterize the impact of Article XXIV on the equilibrium structures and welfare. Conclusions are drawn in Section 6.

\footnotetext{
${ }^{7}$ Article XXIV has also been studied in relation to the Most Favored Nation (MFN) principle by Bagwell and Staiger $(1998,1999,2002)$. They identify the MFN principle as one of the two 'pillars of the GATT,' showing that (in the absence of other distortions) it guides countries to an efficient trade agreement. Since the MFN principle stipulates that any trade concession granted to one country is automatically granted to all, Article XXIV allows an exception to MFN and hence may preclude an efficient trade agreement. Note that Article XXIV is not the main focus of Bagwell and Staiger's analysis and they do not actually study equilibrium under its conditions.

${ }^{8}$ The literature on the dynamics of trade liberalization examines the possibility that trade agreements give way to world free trade at a later stage; see Riezman (1999), Aghion et al. (2007), Seidmann (2009) and Saggi et al. (2010) for recent contributions. Building on Baldwin (1996), Krishna (1998) shows how political interests can undermine the progression from regionalism. Ornelas (2005b) shows that trade agreements may create problems for multilateral trade liberalization 'through their own success'; if governments can adjust tariffs then they only support trade-creating TAs, but then non-member countries may prefer to free-ride on such agreements, blocking a subsequent move to free trade. Ethier (1998) considers how multilateral liberalization may give way to regionalism. See Bhagwati et al. (1998) and Freund and Ornelas (2010) for a literature review on the dynamics of regionalism.
} 


\section{The model and the Article XXIV constraint}

\subsection{Benchmark model of unconstrained CU formation}

In this subsection, we summarize the key characteristics and results of Yi's (1996) model, which we adopt as our benchmark. In the following subsection, we introduce the Article XXIV constraint into the model.

\subsubsection{Preferences and technology}

There are $N$ countries in the model. Each country $i$ has a representative consumer, firm, and government. There are two goods in the model, denoted $M$ and $Q$. Good $M$ is chosen as the numéraire. It is transferred internationally to settle the balance of trade. By assumption, each country is endowed with a sufficient quantity of $M$ to ensure that it consumes a positive quantity in equilibrium. The term $M_{i}$ measures consumption of $M$ in country $i$.

Each firm, one in every country, produces a different variety of the horizontally differentiated product $Q$, at a constant marginal cost $c$ in terms of the numéraire good. Consumers have quasilinear-quadratic preferences of the form

$$
u\left(\mathbf{q}_{i}, M_{i}\right)=v\left(\mathbf{q}_{i}\right)+M_{i}=a Q_{i}-\frac{\gamma}{2} Q_{i}^{2}-\frac{1-\gamma}{2} \sum_{j=1}^{N} q_{i j}^{2}+M_{i}
$$

where $q_{i j}$ is country $i$ 's consumption of country $j$ 's variety of $Q, \mathbf{q}_{i}=\left(q_{i 1}, q_{i 2}, \ldots, q_{i N}\right)$ is country $i$ 's consumption profile, and $Q_{i} \equiv \sum_{j=1}^{N} q_{i j}$. The parameter $\gamma$ is a substitution index between varieties which ranges from 0 (varieties are independent) to 1 (the good is homogeneous); as $\gamma$ increases, the varieties become closer substitutes. The parameter $\gamma$ determines consumers' love for variety: for low values of $\gamma$, variety is highly valued; for higher values of $\gamma$, variety does not matter so much; and when $\gamma=1$, variety is completely unimportant.

There are no transportation costs in this model. Countries impose specific tariffs on imports from other countries. $\tau_{i j}$ denotes country $i$ 's tariff on imports from country $j$. Firms perceive markets as being segmented, and so they compete by choosing quantities in each country. In equilibrium,

$$
Q_{i}=\frac{N-T_{i}}{\Gamma(N)} \quad \text { and } \quad q_{i j}=\frac{\Gamma(0)+\gamma T_{i}-\Gamma(N) \tau_{i j}}{\Gamma(0) \Gamma(N)}
$$

where $T_{i} \equiv \sum_{j=1}^{N} \tau_{i j}$ is the sum of tariffs imposed by country $i ; \Gamma(k) \equiv 2-\gamma+k \gamma, k=0, \ldots, N$; and where we have normalized $a-c=1$. Notice that the parameter $\gamma$ also determines the degree of competition between firms: when $\gamma=0$, firms do not compete with each other, 
but as $\gamma$ increases so does the strategic interaction between firms.

There are two sources of gains from trade: access to a wider variety of goods and increased competition in the domestic market. The importance of each of these gains depends on the substitution index $\gamma$.

\subsubsection{CUs and optimal tariffs}

Country $i$ 's welfare is the sum of four components: domestic consumer surplus $C S^{i}$; domestic firm's profit in the home market $\pi^{i i}$; tariff revenue $T R^{i}$; and domestic firm's export profits $\pi^{j i}, j \neq i$. When forming a $\mathrm{CU}$, countries are assumed to abolish tariffs among union members and jointly set a common external tariff (CET) to maximize the aggregate welfare of members. Thus, if countries $1, \ldots, k$ belong to a CU of size $k$, to set their CET, they solve

$$
\max _{\substack{\left\{\tau_{i j}\right\} \\ i=1, k ; j=k+1, N}} \sum_{i=1}^{k} W^{i}=\sum_{i=1}^{k}\left\{C S^{i}+\pi^{i i}+T R^{i}+\sum_{\substack{j=1 \\ j \neq i}}^{N} \pi^{j i}\right\}
$$

where $\tau_{i j}=0$, for $i=1, \ldots, k$ and $j=1, \ldots, k$. As Yi (1996) shows, the unique optimal CET of a $\mathrm{CU}$ of size $k$ is

$$
\tau(k)=\frac{\Gamma(0) \Gamma(2 k)}{D(k)}
$$

with $D(k) \equiv \Psi(k) \Gamma(N)+\Gamma(k) \Gamma(2 k)$ and $\Psi(k) \equiv[\Gamma(0)+1] \Gamma(k)-\Gamma(2 k)=\Gamma(0)+(1-\gamma) \Gamma(k)$. Note that in this model, the CET of a CU of size $k$ depends only on the size of the CU and the parameters of the model $N$ and $\gamma$. It does not depend on the tariffs set by the rest of the world. This property is driven by the assumptions of segmented markets, quasilinear utility function and constant marginal cost, and will play an important role in the subsequent analysis of the welfare effects of $\mathrm{CU}$ formation.

\subsection{The Article XXIV constraint}

As a CU expands, its CET varies with size of the union $k$ in a non-monotonic way depending on the parameters $\gamma$ and $N$. The numerator of $\tau(k)$ is linear in $k$ while the denominator is a quadratic in $k$ and $\tau(k)$ has only one positive turning point: $\tau(k)$ increases with $k$ if and only if

$$
k<k^{*}(N, \gamma)=\frac{\sqrt{\Gamma(0)[\Gamma(0)+1] \Gamma(N)}-\Gamma(0)}{2 \gamma}
$$

So an expanding CU will raise its CET until it reaches the critical size of $k^{*}$ members. If it expands beyond this size, its CET will decrease. This non-monotonicity of $\tau(k)$ is the result of two opposing effects of CU formation on the CET: a market-power effect and a trade-diversion effect. When members of a CU coordinate over tariff setting, each member internalizes the external benefit to the profits of firms in other member countries of an 
increase in its own tariff, which tends to put upward pressure on the CET. On the other hand, when members of a CU remove internal tariffs there is trade diversion towards goods produced by members and away from the rest of the world. ${ }^{9}$ Since, all else equal, consumers prefer a more balanced consumption bundle, there is an incentive to lower the CET in order to offset this trade diversion. Which of these effects dominates depends on the parameters $\gamma$ and $N$. For low values of $\gamma$, when goods are not substitutable, CU expansion does not divert trade much. The market-power effect dominates and $\tau(k)$ is an increasing function in the relevant range $k \in[1, N]$. ( $k^{*}$ is large and outside the relevant range: $k^{*} \geq N$.) For high values of $\gamma, \mathrm{CU}$ expansion diverts trade in a significant way and when the expanding CU reaches the critical size $k^{*}$ (within the relevant range for high values of $\gamma: k^{*}<N$ ), the trade-diversion effect starts to dominate and $\tau(k)$ is a decreasing function beyond $k^{*}$. These variations are illustrated in Figure 1. Panel 1(a) shows the case of small $N$. Note that for $\gamma=1, k^{*}(N, 1)=\frac{\sqrt{2(N+1)}-1}{2}$. So for small $N$ and $\gamma=1, k^{*}(N, 1) \leq 1$ and $\tau(k)$ is a monotonically decreasing function in the relevant range $k \in[1, N]$. This case occurs only for a very limited range of parameters, when $N$ is very small and $\gamma$ close to 1 , when the trade diversion effect is the strongest. ${ }^{10}$ For larger values of $N$ and high values of $\gamma$, $\tau(k)$ initially increases but eventually decreases in $k$ as shown in panel 1(b). For any $N$ and a sufficiently small $\gamma, k^{*}>N$ and $\tau(k)$ is a monotonically increasing function of $k$ in the relevant range $[1, N]$ as can be seen in both panels $1(\mathrm{a})$ and $1(\mathrm{~b})$. Finally, when $\gamma=0$, the CET is constant and equal to $1 / 3$.

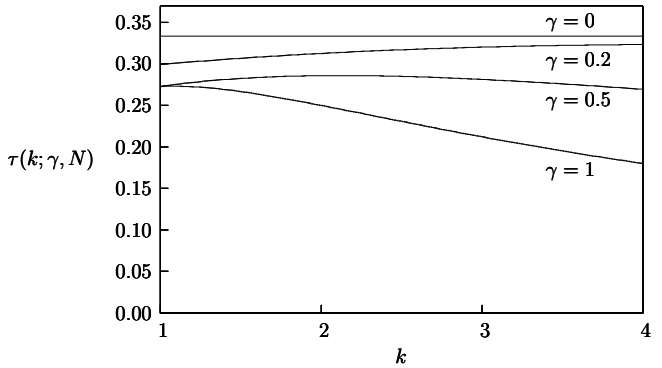

(a) $N=4$

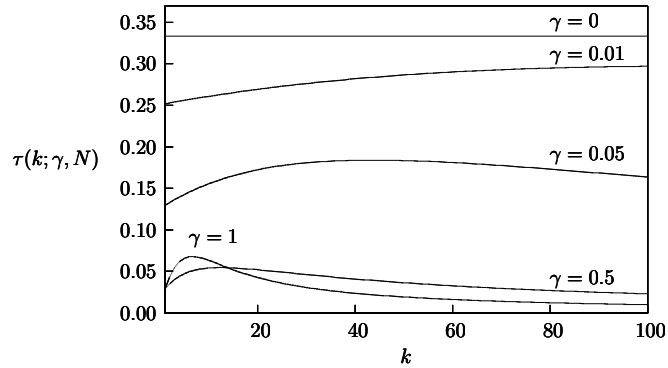

(b) $N=100$

Figure 1: External tariff $\tau(k)$ as a function of the CU size for different values of $N$ and $\gamma$.

Given the properties of the CET, the Article XXIV constraint can be formalized in a simple way. To set the level of the Article XXIV constraint we will assume that initially there are no CUs. Since all countries are symmetric, they all initially impose the same Nash tariff $\tau(1)$. Then, if a set of countries forms a CU, and is obliged to abide by Article

\footnotetext{
${ }^{9}$ Note that by trade diversion we mean simply an increase in the trade with members accompanied by a decrease in the trade with non-members. Given that all countries have the same technology in our model, we abstract from any efficiency considerations, contrary to Viner (1950).

${ }^{10}$ For small $N$, adding one more country into a $\mathrm{CU}$ represents a large proportion of world trade and so trade diversion dominates from the start.
} 
XXIV, their external tariff is constrained to be less than or equal to $\tau(1)$. The effect of the Article XXIV constraint depends on the form of the function $\tau(k)$. If, for example, $\tau(k)$ is a decreasing function in the relevant range, then the Article XXIV constraint is not binding and has no effect. On the other hand, if $\tau(k)$ is initially an increasing function and becomes a decreasing function only for higher values of $k$, then there will be a range of $k$ for which the Article XXIV constraint will bind. The following proposition identifies when the Article XXIV constraint binds and when it does not. See the Appendix for the proof.

Proposition 1. For a number of countries in the world $N$ and substitution index $\gamma$, the Article XXIV constraint is binding for any size- $k C U, k \leq k^{* *}(N, \gamma)$, where $k^{* *}(N, \gamma)$ is the non-trivial root of $\tau(k)=\tau(1)$ :

$$
k^{* *}(N, \gamma)=\frac{\Gamma(0)\{\Gamma(N)[\Gamma(0)+1]-\Gamma(2)\}}{2 \gamma \Gamma(2)}
$$

The Article XIV constraint imposes

$$
\tau_{c}(k)= \begin{cases}\tau(1) & \text { for } 1 \leq k \leq k^{* *}(N, \gamma) \\ \tau(k) & \text { for } k^{* *}(N, \gamma)<k<N \text { and } \\ 0 & \text { for } k=N\end{cases}
$$

Figure 2 illustrates $\tau_{c}(k)$ as a function of $\mathrm{CU}$ size. Note that $\tau_{c}(k)$ is a non-increasing function of $k$.

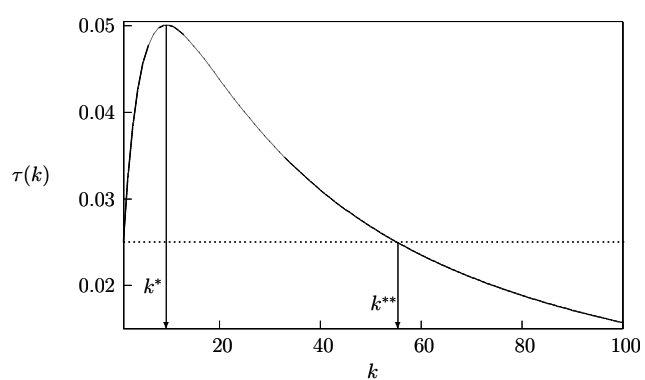

(a) $\tau(k)$

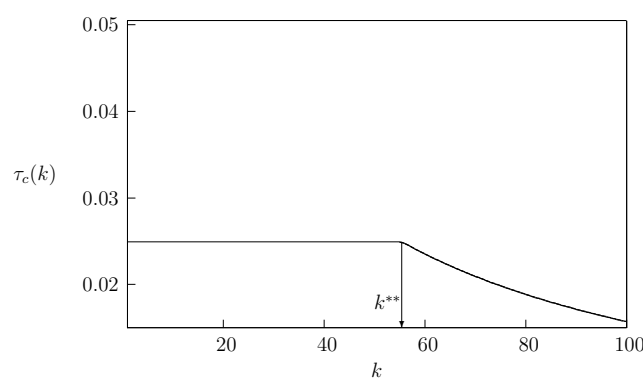

(b) $\tau_{c}(k)$

Figure 2: $\tau(k)$ and $\tau_{c}(k)$ for $N=100$ and $\gamma=0.7$.

The online appendix analyzes in detail the properties of $k^{* *}$. It is however useful to point out some of the key characteristics that will be crucial for the derivation of the main results in later sections: $k^{* *}(N, \gamma)$ is a linear (monotonically increasing) function of $N$ (when $\gamma \neq 0$ ), and a continuous and monotonically decreasing function of $\gamma$ for $\gamma \in(0,1]$ with $k^{* *}(N, 1)=$ $\frac{2 N-1}{6}$. Hence we know that any $C U$ of size smaller than $\frac{2 N-1}{6}$ will always (for any $N$ and $\gamma$ ) be bound by the Article XXIV constraint. Furthermore, when $\gamma \rightarrow 0^{+}, k^{* *} \rightarrow+\infty$, and when $\gamma=1, k^{* *}$ is strictly positive and smaller than $N$. Thus, by the intermediate value theorem, there exists a unique value of $\gamma$, denoted $\gamma_{N}(N)$, such that $k^{* *}\left[N, \gamma_{N}(N)\right]=N$. 
Hence we know that for a given $N$ and for $\gamma \in\left[0, \gamma_{N}(N)\right]$, Article XXIV binds for any possible CU. It can be shown that $\gamma_{N}(N)$ is a monotonically decreasing function of $N$ with $\gamma_{N}(1)=7-\sqrt{41} \approx 0.597$ and it approaches a horizontal asymptote when $N$ tends to infinity: $\lim _{N \rightarrow+\infty} \gamma_{N}(N)=\gamma_{N \infty} \equiv \frac{1}{2}(7-\sqrt{41}) \approx 0.298$. And so for any $N$ and $\gamma \in\left[0, \frac{1}{2}(7-\sqrt{41})\right]$, any $\mathrm{CU}$ is bound by Article XXIV.

Similarly, we can find the unique value of $\gamma$, denoted $\gamma_{\frac{N}{2}}$, such that $k^{* *}=\frac{N}{2}: \gamma_{\frac{N}{2}}=$ $3-\sqrt{5} \approx 0.764$. Note that $\gamma_{\frac{N}{2}}$ is a constant, independent of $N$. We know that for any $N$ and $\gamma \in[3-\sqrt{5}, 1]$, the Article XXIV constraint does not bind for CUs containing more than half of the countries in the world. These features are illustrated in Figure 3: CUs of size smaller than $k^{* *}$ ( $k$ below the $k^{* *}$ curve) are constrained by Article XXIV while CUs of size larger than $k^{* *}$ ( $k$ above the $k^{* *}$ curve) are not. For $\gamma \leq \gamma_{N}$, all possible CUs are constrained. For $\gamma>\gamma_{\frac{N}{2}}$, any CUs containing more than $N / 2$ countries are not constrained.

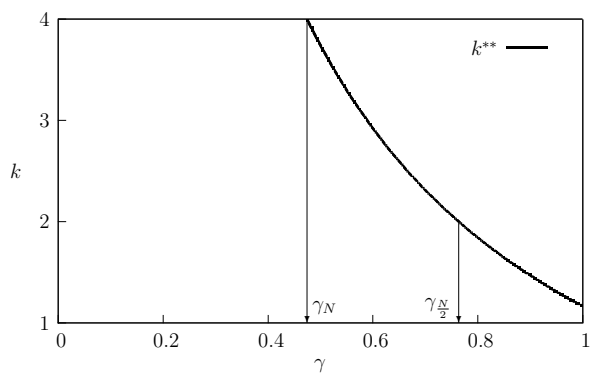

(a) $N=4$

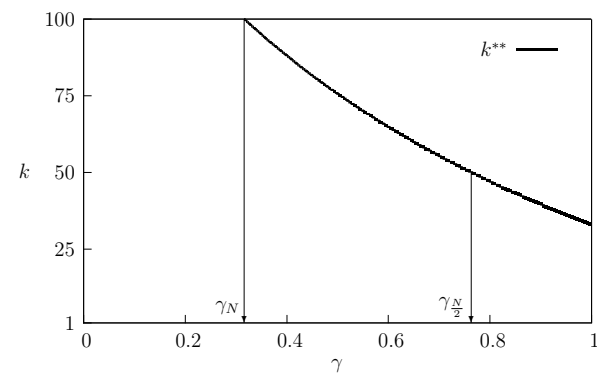

(b) $N=100$

Figure 3: $k^{* *}$ as a function of $\gamma$.

Having characterized the Article XXIV constraint, we can now study the effects of Article XXIV on CU formation and on welfare.

\section{CU formation and welfare}

In this section, we analyze the impact of an (exogenous) formation or expansion of a $\mathrm{CU}$ under the Article XXIV constraint on the welfare of individual countries and on global welfare. Our analysis proceeds along the same lines as Yi (1996) but with the key difference that all CUs have to abide by Article XXIV. We show that the Article XXIV constraint attenuates the negative effects of $\mathrm{CU}$ formation, but does not prevent them altogether.

\subsection{Preliminaries}

The impact of CU formation and expansion on members' and non-members' welfare can be studied through the following quantities which can be derived from (2): sales of a member nation (Insider) $q_{I}(k)$ and sales of a non-member nation (Outsider) $q_{O}(k)$ in a country 
belonging to a size- $k$ CU

$$
q_{I}(k)=\frac{\Gamma(0)+[\Gamma(N)-\Gamma(k)] \tau_{c}(k)}{\Gamma(0) \Gamma(N)} \text { and } q_{O}(k)=\frac{\Gamma(0)-\Gamma(k) \tau_{c}(k)}{\Gamma(0) \Gamma(N)}
$$

and total consumption $Q(k)$ in a country belonging to a size- $k \mathrm{CU}$

$$
Q(k)=\frac{N-(N-k) \tau_{c}(k)}{\Gamma(N)}
$$

\subsection{Non-members' welfare}

We can see by inspection of $(6)$ that $q_{I}(k)$ exceeds $q_{O}(k)$; i.e. a member country always sells a higher volume of exports in a member country than a non-member country. Since the expression for export profits is the square of the expression for export volume, a member country makes higher export profits in any member country than a non-member country. Furthermore, a non-member country is affected by CU formation or expansion only through its export profits to the CUs that form. So from (6), we can show that non-member countries become worse off if a CU expands. Yi (1996) shows this result without the Article XXIV constraint, reflecting a standard property in the literature that $\mathrm{CU}$ formation and expansion tend to hurt non-members through trade diversion. In the following Lemma, we show that the Article XXIV constraint is not sufficient to prevent the harmful trade diversion effect, but attenuates it slightly. See the Appendix for the proof.

Lemma 1. 1. A non-member country's exports $q_{O}(k)$ are a decreasing function of $k$ and so a non-member country becomes worse off if a $C U$ expands.

2. When the Article XXIV constraint binds, a non-member country's exports $q_{O}(k)$ decrease less in $k$ compared to the situation without the Article XXIV constraint.

\subsection{Members' welfare}

How does an expansion of a CU affect the welfare of member countries? Without Article XXIV, all the components of welfare (consumer surplus, tariff revenue and producer surplus) are affected in an ambiguous way. As a CU expands, there are two effects on the consumer surplus of a member country: consumer surplus tends to increase through the increased consumption of products from member countries, but it tends to decrease through the diminished consumption of non-member countries' products. Tariff revenue may also increase or decrease as the CET may increase as a CU expands while the number of taxed importers decreases. Finally, the home firm's export profits in new members' markets increase due to tariff-free access to these markets, but home firm's profits in existing members' markets may either increase or decrease: each firm faces competition from more other members' firms, but, at the same time, it may face less competition from outsiders' firms when the 
CET rises. So the effect on home firm's total profit is also ambiguous. As shown in the following lemma, Article XXIV changes somewhat how a CU expansion affects the different components of members' welfare.

Lemma 2. As a CU expands, a representative member's

1. consumer surplus unambiguously increases,

2. tariff revenue unambiguously falls,

3. home firm's export profits in new members' markets increase, but domestic profit and export profits in existing members' markets decrease and so the total profits are affected in an ambiguous way.

Thus the effect of a $C U$ expansion on welfare of member countries is ambiguous.

The proof in the Appendix shows analytically that consumer surplus is an increasing function of the size of the CU when Article XXIV is in place. The intuition for this result is that consumers will still benefit from the increased consumption of products from member countries and they will still be harmed by the diminished consumption of non-member countries' products, but the Article XXIV constraint, by preventing member countries from raising the external tariff above the initial level, makes the second effect less important (Lemma 1). The tariff revenue necessarily decreases as the CU expands, because countries are not allowed to raise their external tariffs, and as the CU expands they can thus levy at most the same level of tariff on fewer countries. Finally, the effect of CU expansion on domestic firm's total profits is still ambiguous, however, with Article XXIV, the profit made at home and in existing members' markets unambiguously decrease as the domestic firm faces more competition from other members' firms and is less protected from the competition of non-members' firms. On the whole, the effect of CU expansion on the welfare of a member country is ambiguous.

While we are not able to obtain a general prediction about how CU expansion will affect the welfare of an individual member, we can show that the joint welfare of the member countries (existing members plus any new members) improves when a CU expands. (In the case where existing members lose, new members gain by more than enough to compensate.) This implies that, if several CUs merge, the aggregate welfare of members of the newly formed CU increases. While this result is established by Yi (1996) for the case without Article XXIV, we show that it continues to hold under the Article XXIV constraint.

Lemma 3. Under the Article XXIV constraint, the formation or expansion of CUs increases the aggregate welfare of member countries.

See the Appendix for a summary of the proof; full details are given in the online Appendix. 


\subsection{World welfare}

What is the effect of CU formation and expansion on world welfare? As Yi (1996) points out, without the Article XXIV constraint, as a CU expands, its members are on average better off, but non-members are made worse off, so the effect on world welfare is ambiguous, except when global free trade is reached where world welfare is maximized. ${ }^{11}$ As we have shown above, the presence of Article XXIV does not reverse any of these effects. In particular, Article XXIV is not sufficient to prevent the harmful effects of CU formation on non-members, and so the effect on world welfare also appears ambiguous except for the global free trade case. However, Article XXIV affects the magnitude of these effects, namely it reduces the harm to non-members, so it may be possible that on the whole CU expansion with the Article XXIV constraint increases world welfare. We cannot conclude at this stage. To evaluate the effects of CU formation on world welfare we need to examine the link between CU structures and welfare which we do in the next section.

\section{CU structures and welfare}

\subsection{CU structures and individual members' welfare}

In Subsection 3.3, we showed that the formation and expansion of a CU has an ambiguous impact on individual-member welfare. In fact, circumstances do exist under which we can clearly predict that member welfare will increase under CU expansion. We determine these conditions by exploring how welfare depends on CU structures.

Definition 1. Let $\mathcal{P}$ be the set of countries: $\mathcal{P}=\left\{P_{1}, P_{2}, \ldots, P_{N}\right\}$. A CU structure $C=$ $\left\{B_{1}, B_{2}, \ldots, B_{m}\right\}$ is a partition of the set of countries $\mathcal{P}$ into $m$ CUs. $B_{i} \cap B_{j}=\varnothing$ for $i \neq j$ and $\cup_{i=1}^{m} B_{i}=\mathcal{P}$.

Since countries are symmetric, we can identify each CU with the number of its members. In what follows, we will use the same notation as Yi (1996) and write $C=\left\{n_{1}, n_{2}, \ldots, n_{m}\right\}$, where $n_{i}$ is the number of countries in the $i$ th $\mathrm{CU}$ in $C=\left\{B_{1}, B_{2}, \ldots, B_{m}\right\}$. Both with and without the Article XXIV constraint, the tariff equilibrium is unique for any given $\mathrm{CU}$ structure and so the welfare of a $\mathrm{CU}$ of size $k$ in any $\mathrm{CU}$ structure is well defined. Following Yi (1996), we will denote the welfare of a member country of a CU of size $k$ in a given $\mathrm{CU}$ structure $C$ as $W(k ; C), k=n_{1}, n_{2}, \ldots, n_{m}$. For example, in a CU structure $C=\{2,3,4\}$, $W(3 ;\{2,3,4\})$ is the level of welfare of a country belonging to the three-country CU.

Lemma 4. The welfare of a member of the size- $n_{i} C U$ in $C=\left\{n_{1}, n_{2}, \ldots, n_{m}\right\}$ is given by

$$
W\left(n_{i} ; C\right)=N S\left(n_{i}\right)+P B\left(n_{i} ; C\right)
$$

\footnotetext{
${ }^{11}$ Global free trade corresponds to the formation of one grand CU containing all the countries.
} 
where $N S\left(n_{i}\right) \equiv Q\left(n_{i}\right)-\frac{\gamma}{2} Q\left(n_{i}\right)^{2}-\frac{1-\gamma}{2}\left\{n_{i}\left[q_{I}\left(n_{i}\right)\right]^{2}+\left(N-n_{i}\right)\left[q_{O}\left(n_{i}\right)\right]^{2}\right\}$ is the net benefit from consumption and $P B\left(n_{i} ; C\right) \equiv \sum_{\substack{j=1 \\ j \neq i}}^{m} n_{j} q_{O}\left(n_{j}\right)^{2}-\left(N-n_{i}\right)\left[q_{O}\left(n_{i}\right)\right]^{2}$ is the profit balance. Proof. The welfare of Country $i$ is $W^{i}=C S^{i}+\pi^{i i}+T R^{i}+\sum_{\substack{j=1 \\ j \neq i}}^{N} \pi^{j i}$. Noting that $C S^{i}+\pi^{i i}+T R^{i}=\frac{\gamma}{2} Q_{i}^{2}+\frac{1-\gamma}{2} \sum_{j=1}^{N} q_{i j}^{2}+\pi^{i i}+T R^{i}=u\left(\mathbf{q}_{i}\right)-c Q_{i}-\sum_{\substack{j=1 \\ j \neq i}}^{N} \pi^{i j}$, we have $W^{i}=\underbrace{v\left(\mathbf{q}_{i}\right)-c Q_{i}}_{N S}+\underbrace{\sum_{\substack{j=1 \\ j \neq i}}^{N} \pi^{j i}-\sum_{\substack{j=1 \\ j \neq i}}^{N} \pi^{i j}}_{P B}$ and the result follows.

The following results illustrate how the CU structure affects individual member welfare under the Article XXIV constraint. These results are analogous to the propositions derived by Yi (1996). We prove that Yi's results (his propositions 6-8) continue to hold under the Article XXIV constraint and discuss what the differences are with respect to the situation without the Article XXIV constraint. These results will be crucial in determining the stable CU structures of the CU formation game in Section 5.

Lemma 5. 1. If $n_{i} \in C, C^{\prime}$, and $C-\left\{n_{i}\right\}$ can be derived from $C^{\prime}-\left\{n_{i}\right\}$ by merging $C U s$ in $C^{\prime}-\left\{n_{i}\right\}$, then $W\left(n_{i} ; C\right)<W\left(n_{i} ; C^{\prime}\right)$.

2. If $n_{i}>n_{j}$, then $W\left(n_{i} ; C\right)>W\left(n_{j}, C\right)$.

3. The members of a $C U$ that merges with another $C U$ of equal or larger size become better off.

4. A member of a $C U$ becomes better off if it leaves its $C U$ to join another $C U$ of equal or larger size.

Proof. The qualitative properties of the welfare components $q_{O}(k)$ and $N S(k)$ are the same as in Yi (1996) and so Yi's proofs of his propositions 6-8 (pages 163-164) apply with the appropriate amendments (the Nash CET function $\tau\left(n_{i}\right)$ is replaced by the Article XXIVconstrained $\left.\operatorname{CET} \tau_{c}\left(n_{i}\right)\right)$.

Although the proofs of these results are identical to the equivalent results of Yi except that ours replace the general tariff, $\tau\left(n_{i}\right)$, with our tariff on which the Article XXIV constraint may be binding $\tau_{c}\left(n_{i}\right)$, it may be helpful to provide some brief intuition. The first point of Lemma 5 says that if CUs merge to form a larger CU, non-member countries not involved in the merger are made worse off. This result is a consequence of Lemma 1: as any CU expands, the export profits made by non-members unambiguously fall, and this is the only 
effect of $\mathrm{CU}$ expansion on non-members. Also from Lemma 1 we know that the Article XXIV constraint will attenuate the adverse effect of a CU merger on non-members.

The second point ranks the per-member welfare of CUs in a given CU structure: in any given CU structure, a member of a large CU has a higher level of welfare than does a member of a small CU. This result holds both under the Article XXIV constraint and without it, but the impact of Article XXIV is ambiguous and will depend on the given CU structure. If the Article XXIV constraint binds for small CUs but not for large ones (which is the case if $\gamma$ is relatively large), the difference in welfare of a member of a large $\mathrm{CU}$ and a member of a small CU will be exacerbated. However, if the Article XXIV constraint binds for both large and small CUs, this difference may be attenuated.

The final two points show how changes in the CU structure affect the welfare of countries involved in the change. When CUs merge, the welfare of members increases on average. Before the merger, the members of the smallest CU involved have the lowest welfare among the CUs involved, and thus their welfare must have necessarily increased by the merger. ${ }^{12}$

Imposition of the Article XXIV constraint does not reverse any of Yi's equivalent results. It only modifies the magnitude of the effect of $\mathrm{CU}$ formation on welfare. This will in turn have important implications for the final equilibrium $\mathrm{CU}$ structure with and without the Article XXIV constraint and for world welfare as we will show in Section 5.

\subsection{CU structures and world welfare}

Having understood the link between CU structures and welfare, we can now look more in depth at the effects of CU formation under Article XXIV on world welfare.

Lemma 6. In a $C U$ structure $C=\left\{n_{1}, n_{2}, \ldots, n_{m}\right\}$, the world welfare is given by

$$
W_{W}(C)=\sum_{i=1}^{m} n_{i} W\left(n_{i}, C\right)=\sum_{i=1}^{m} n_{i} N S\left(n_{i}\right)
$$

Proof. World welfare is the sum of welfare of all the individual countries (8). The profitbalance part of individual countries' welfare cancels out, because for the world as a whole, the profit balance is zero. And so the world welfare is the sum of the individual countries' net benefits from consumption.

To disentangle the different effects of Article XXIV, we start by determining the impact of Article XXIV on world welfare for a given CU structure. See the Appendix for the proof.

\footnotetext{
${ }^{12}$ Note that given the fact that two CUs of the same size are always better off by merging, if countries were allowed to form only symmetric blocs as in Krugman (1991), they would always want to form one large bloc containing all countries, i.e. go to free trade. Thus in our model, free trade would be the stable equilibrium outcome if only symmetric blocs were allowed. This result is shown by Oladi and Beladi (2008) in a different setting using the Krugman (1991) model. The difference of this paper is that we do not impose the symmetry constraint on the CU structure, and, as we show in Section 5, symmetric blocs are not an equilibrium outcome of the $\mathrm{CU}$ formation game considered in this paper.
} 
Proposition 2. For a given CU structure, the Article XXIV constraint weakly increases world welfare.

The intuition for this result is clear: Article XXIV lowers CETs of CUs when it binds (and has no effect when it does not bind) and so for a given CU structure, Article XXIV reduces barriers to trade and so improves world welfare.

How does a CU expansion affect world welfare under Article XXIV? As we have already mentioned in Section 3, Yi (1996) shows that, without the Article XXIV constraint, the effect of a CU expansion on world welfare is ambiguous (except when free trade is reached). Article XXIV attenuates some of the negative effects of $\mathrm{CU}$ formation and it makes it possible for CU expansion to be world welfare increasing under certain conditions. The following proposition provides a sufficient condition under which a $\mathrm{CU}$ expansion increases world welfare under Article XXIV. See the Appendix for a summary of the proof; full details are given in the online Appendix.

Proposition 3. Assume $N \geq 6$ and consider a given $C U$ structure $C=\left\{n_{1}, n_{2}, \ldots, n_{m}\right\}$. Within $C$, consider any two CUs $i$ and $j$ such that $n_{i} \geq n_{j}$. Assume that the Article XXIV constraint is binding at least on union $j$. Expansion of $C U i$, by accepting countries from the smaller or equal-sized union $j$, increases world welfare if $n_{i}+n_{j} \geq \frac{2 N}{3}$.

The intuition behind this result is that CU expansion increases members' welfare while hurting outsiders. So if there are not many outsiders and if the Article XXIV constraint binds on the small union such that the expanding union is even better off than when it expands in the absence of Article XXIV (where the small union could increase its tariff), world welfare increases on average.

Proposition 3 thus reveals another potential world-welfare increasing effect of Article XXIV: Article XXIV is not sufficient to prevent the harmful effects of a CU expansion on world welfare in all cases, but it does prevent them in many cases. ${ }^{13}$

An important consequence of Proposition 3 is that if the world is divided into only two blocs, an increase in the asymmetry between these blocs increases world welfare (with free trade being the extreme case that maximizes world welfare). Note that this is not necessarily true in the absence of Article XXIV (it is very easy to find counter-examples) because the smaller union when becoming smaller could raise its CET and thus reduce the benefits to the members of the larger expanding union.

\footnotetext{
${ }^{13}$ Note that the condition given by Proposition 3 is only a sufficient condition, it is not a necessary condition. The necessary condition for the expansion of $\mathrm{CU} i$ to be world-welfare increasing when $\mathrm{CU} j$ is bound by Article XXIV is much weaker: the combined size of the two unions involved in the transformation $n_{i}+n_{j}$ has to be greater than a certain threshold which varies with the parameters of the model $N$ and $\gamma$ and ranges from 0 to $\frac{2 N}{3}$. The exact threshold is derived in the online Appendix. It does not present any particular interest for our analysis.
} 


\section{CU formation equilibria and Article XXIV}

The previous sections showed that the Article XXIV constraint slightly attenuates some of the negative effects of exogenous $\mathrm{CU}$ formation and expansion. Outsiders are made less worse off by the formation of a CU (Article XXIV is however insufficient to reverse this negative effect completely) and CU expansion becomes world-welfare improving under certain conditions. These intermediate results might suggest that the effect of Article XXIV, if any, is mildly positive and relatively unimportant. In this section, we analyze the effects of Article XXIV on endogenous CU formation. We show that the Article XXIV constraint affects the incentives for $\mathrm{CU}$ formation and thus affects the final equilibrium CU structure, with important, possibly negative, implications for world welfare.

\subsection{CU formation game}

We follow Yi (1996) in using an infinite-horizon sequential-move 'coalition unanimity game' to model the $\mathrm{CU}$ formation process. In this game, a coalition forms if and only if all potential members agree to form the coalition. ${ }^{14}$ Bloch (1996) shows that this game yields the same stationary subgame perfect equilibrium coalition structure as the following 'size announcement game'. All countries are placed on a list, say $P_{1}, P_{2}, \ldots, P_{N}$. Country $P_{1}$ is asked to announce the size of the $\mathrm{CU}$ that it would like to form, e.g. $k$. Then the first $k$ countries form a size- $k \mathrm{CU}$, and then country $P_{k+1}$ announces the size of the $\mathrm{CU}$ it would like to form, and so on until $P_{N}$ is reached. Bloch (1996) shows that this size announcement game has a (generically) unique subgame perfect equilibrium coalition structure. We will now use this size announcement game to determine stable CU structures of the CU formation process. ${ }^{15}$

\subsection{Characterization of stable CU structures}

In this subsection, we characterize stable CU structures when countries play the size announcement game characterized above. In order to do so, let us define $k_{0}$ as the largest integer such that any size- $k C U, k \leq k_{0}$, becomes better off by merging with a single-country $C U$. Formally:

\footnotetext{
${ }^{14}$ The country $P_{1}$ starts the game by proposing the formation of a CU, e.g. $\left\{P_{1}, P_{3}, P_{7}, P_{8}\right\}$. Then all proposed partners (following subsequently from country $P_{1}$ ) are asked to agree or disagree. If a proposed CU partner disagrees then it is asked to make its own proposal of a $\mathrm{CU}$ and, again, each subsequent proposed partner of the $\mathrm{CU}$ is asked whether or not it agrees. If all agree then the $\mathrm{CU}$ forms and those countries withdraw from the game. Then the first country among the remaining countries makes a proposal.

${ }^{15}$ Note that side-payments between countries are not allowed in the CU formation process. If they were, then it would be possible to reach free trade under any set of parameter values. While they do occur in practice, it appears that political constraints coupled with credit market imperfections mean that sidepayments between countries are not large enough to facilitate free trade.
} 
Definition 2. For all CU structures $C$ and $C^{\prime}, C^{\prime}=C-\{k\} \cup\{k-1,1\}$, and all $k$, $1 \leq k \leq k_{0}, k_{0}$ is the largest integer which satisfies $W(k ; C) \geq W\left(k-1 ; C^{\prime}\right)$.

The following Lemma characterizes stable CU structures of the size announcement game. A summary proof of this and the other results in this Section are in the Appendix. Detailed proofs can be found in the online Appendix.

Lemma 7. 1. Under the Article XXIV constraint, the unique subgame perfect equilibrium $C U$ structure of the size announcement game has a unique smallest $C U$, which is the last $C U$ to form.

2. Under the Article XXIV constraint, the unique subgame perfect equilibrium CU structure of the size announcement game has a unique second-smallest $C U$, which is the second-to-last $C U$ to form and which has at least $k_{0}$ members.

3. Under the Article XXIV constraint, the number of equilibrium CUs in the size announcement game is not greater than four. For $\gamma \in\left[0, \frac{1}{2}(13-\sqrt{129})\right]$ or $N \leq 31$, the number of equilibrium $C U$ s is not greater than three, and, for $\gamma=0$, the equilibrium $C U$ structure is global free trade.

The intuition for these results is simple: from Lemma 5, we know that two CUs of equal size would be better off by merging and so the CU equilibrium structure cannot be symmetric. Also, the last $\mathrm{CU}$ to form must be the smallest since it implies the lowest level of welfare for each of its members. If its members had the option to form a larger CU earlier in the process then they would have done so. By the same reasoning, the second-to-last CU to form must be the unique second-smallest CU. Furthermore, it has to have at least $k_{0}$ members, because if it did not, it would be better off by admitting at least one more member. Thus we are able to put a lower bound on the size of the second-to-last CU to form and of all the other larger CUs that form before the second-to-last union. This in turn provides us with an upper bound on the number of CUs in equilibrium which is four CUs for $\gamma \in[0,1]$ and three for $\gamma \in\left[0, \frac{1}{2}(13-\sqrt{129})\right] .{ }^{16}$ When $\gamma=0$, there will be only one CU (the equilibrium is free trade). This is because when goods are independent in demand, the gains from free trade outweigh the gains from foreign rent extraction.

\subsection{Article XXIV and equilibrium CU structures}

We now explore in detail how Article XXIV affects the equilibrium CU structure. It is difficult to find a general closed-form solution for the equilibrium CU structure. ${ }^{17}$ We can however make use of the result, derived in Lemma 7, that there will be at most four CUs in

\footnotetext{
${ }^{16} \mathrm{Yi}$ (1996) showed that in the absence of Article XXIV there will be at most three CUs in equilibrium.

${ }^{17}$ To solve for the equilibrium CU structure, one would need to solve a series of $p^{t h}$ degree polynomial equations with $p \geq 6$ (the degree of the equations depends on which unions are constrained by Article XXIV) where the coefficients of these polynomials are themselves high-degree polynomials in $N$ and $\gamma$.
} 
equilibrium, to run a grid search and determine the equilibrium CU structures numerically. The numerical analysis shows that, for the wide range of parameters covered, there will be actually at most only two CUs in equilibrium (both with or without Article XXIV). Before looking at the numerical results in detail, we derive three additional analytic results which will provide context for the numerical ones.

First, to be able to interpret the effects of Article XXIV, we need to know which equilibrium CUs will be bound by it. In Section 2, we showed that only CUs of smaller size than $k^{* *}(N, \gamma)$ are constrained by Article XXIV. The following Proposition determines which CUs in the $\mathrm{CU}$ formation equilibrium will satisfy this condition assuming that there will be at most two CUs in the equilibrium.

Proposition 4. Assume that there are at most two CUs in equilibrium. When the small $C U$ is not empty,

1. for every $N \geq 5$, there exists a unique $\hat{\gamma}(N) \in\left(\frac{466}{1000}, \frac{476}{1000}\right)$ such that for $\gamma \leq \hat{\gamma}(N)$ Article XXIV binds on the large $C U$ and for $\gamma>\hat{\gamma}(N)$ it does not;

2. Article XXIV always binds on the small $C U$.

Now that we know when and on which CU Article XXIV binds in a two CUs equilibrium, we analyze how it affects the incentives of countries to form CUs. Namely, we look at the local effects of Article XXIV: At the equilibrium point where the large bloc has chosen its size optimally in the presence of Article XXIV, how would its choice be affected if we were to remove Article XXIV and allow CUs to marginally increase their CET?

Proposition 5. Assume that there are at most two CUs in equilibrium. When the small $C U$ is not empty,

1. when Article $X X I V$ binds on the large $C U$, it makes the large $C U$ want to accept more members;

2. when Article XXIV binds on the small CU, it makes the large $C U$ want to accept fewer members.

The intuition for these results is simple: when the large bloc is constrained, it is less able to exploit terms-of-trade and profit-shifting gains from outsiders. Hence gains from free trade with more countries become relatively larger and so the large bloc would want to expand. For the second part of the result, assume that Article XXIV binds on the small bloc. If this constraint is lifted, the small bloc would raise its CET and thus hurt the members of the large bloc. To mitigate this effect, the members of the large bloc would want to accept more members so that they suffer the import tariff rise from fewer countries. Thus, when the small bloc is constrained, the large bloc would want to accept fewer members.

Proposition 5 characterizes local effects of Article XXIV. The next obvious question is whether these local effects translate into a global change in the CU structure when Article 
XXIV is imposed? And if yes, how is the equilibrium CU structure affected by Article XXIV?

Proposition 6. Assume that there are at most two CUs in equilibrium. For $\gamma>\hat{\gamma}(N)$ and $N \geq 139$, the equilibrium $C U$ structure under Article XXIV is strictly more symmetric than without Article XXIV.

From Proposition 4 we know that, for $\gamma>\hat{\gamma}(N)$, only the small CU in a two CU equilibrium structure is constrained by Article XXIV and so only the second effect of Article XXIV (from Proposition 5) can be present. Proposition 6 shows that this local effect translates into a global effect for sufficiently large $N$.

When $\gamma \leq \hat{\gamma}(N)$, both blocs are constrained by Article XXIV, and both local effects of Article XXIV are present. These two effects work in opposite directions. Which effect dominates? Intuitively, when the large union is more constrained by Article XXIV ( $\gamma$ close to 0$)$ the first effect will dominate, and when the small union is more constrained ( $\gamma$ close to $\hat{\gamma}(N))$ the second effect will dominate. This however depends on the parameters on the model and we cannot derive an unambiguous analytic result.

To evaluate the global effects of Article XXIV for the entire range of $\gamma$ we determine equilibrium CU structures both with and without the Article XXIV constraint numerically. To do so, we conduct a grid search over all the possible sizes of the CUs assuming that there will be at most four CUs in equilibrium (for details on the CU formation algorithm see the online Appendix). We run these simulations for $0 \leq \gamma \leq 1$ (incrementing $\gamma$ by $10^{-6}$ ) and for $N=5, \ldots, 10^{5}$. Below we report the results of our numerical analysis. The first result determines the number of CUs in equilibrium.

Result 1. For the range of parameters $N$ and $\gamma$ considered, there are at most two $C U$ s in equilibrium.

The following three results confirm that local effects derived in Proposition 5 correctly predict the global effects of Article XXIV on the equilibrium CU structure.

Result 2. For low values of $\gamma$, Article XXIV leads to a weakly more asymmetric equilibrium $C U$ structure (i.e. the large $C U$ is larger).

Result 2 is illustrated in Figure 4 which shows $k_{L}^{\text {opt }}$, the size of the large CU in the equilibrium CU structure consisting of two asymmetric CUs, with and without Article XXIV. We can see that for low values of $\gamma$, the large CU is weakly larger with Article XXIV than without. Intuitively, for low $\gamma$, the equilibrium $\mathrm{CU}$ structure is weakly more asymmetric with the Article XXIV constraint, because, for low $\gamma$, given the shape of the CET function which is increasing in the size of the bloc, it is the large CUs that are more constrained than small ones, and thus the first effect from Proposition 5 dominates. $^{18}$

\footnotetext{
${ }^{18}$ Note that the range of $\gamma$ for which Result 2 arises becomes smaller as $N$ increases. This is because an
} 


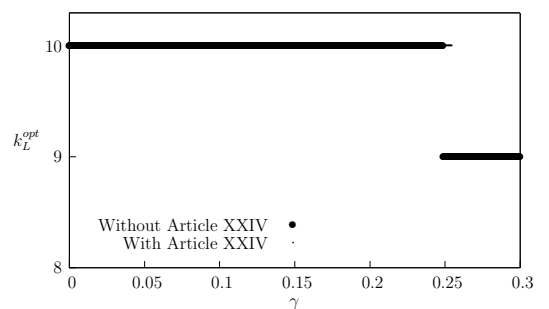

(a) $N=10,0 \leq \gamma \leq 0.3$

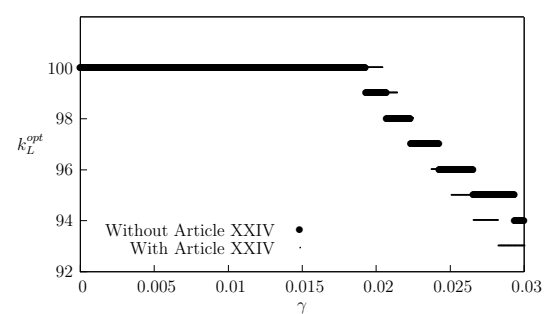

(b) $N=100,0 \leq \gamma \leq 0.03$

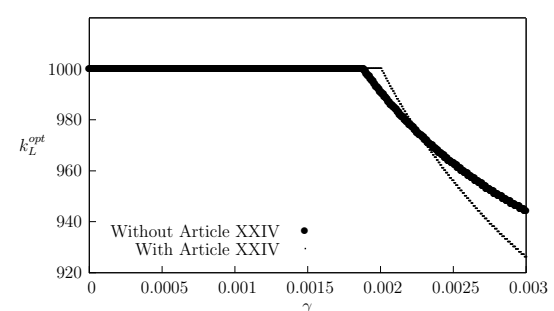

(c) $N=1000,0 \leq \gamma \leq 0.003$

Figure 4: Size of the large bloc in the equilibrium two CU structure for low values of $\gamma$.

Figure 4 also illustrates the result from Lemma 7 that, for $\gamma$ sufficiently close to 0 , the equilibrium CU structure is one large union containing all the countries, i.e. free trade. This is because, when goods are independent, the static efficiency gains of free trade outweigh the terms-of-trade benefits that would arise under CU formation even for a large CU. Thus there is a strong incentive for countries to go to free trade. For higher values of $\gamma$, gains from free trade are relatively smaller than benefits from foreign-rent extraction and so it is beneficial for the large union to leave some countries out of the union.

Yi (1996) shows that, for every $N$, there is a unique threshold value of $\gamma$, which we will denote $\gamma^{F T}(N)$, below which the equilibrium CU structure is free trade. This threshold value is given by $W(N ;\{N\}) \geq W(N-1 ;\{N-1,1\})$. We determine this threshold value of $\gamma$ numerically both with and without the Article XXIV constraint $\left(\gamma_{c}^{F T}\right.$ and $\gamma_{u}^{F T}$ respectively). The following result compares these two thresholds.

Result 3. For $7 \leq N \leq 10^{5}, \gamma_{c}^{F T} \geq \gamma_{u}^{F T}$.

Hence for the range of parameters considered, free trade arises for a wider range of $\gamma$ with Article XXIV than without it. This is because Article XXIV limits foreign rent extraction and so the benefits from free trade outweigh the benefits from foreign rent extraction for a larger range of parameters. ${ }^{19}$ The widening of the range of parameters for which free trade arises is however small and it decreases as $N$ increases as illustrated in Figure 5.

Result 4. For higher values of $\gamma$, Article XXIV leads to a weakly more symmetric equilibrium $C U$ structure (i.e. the large $C U$ is smaller). For $\gamma \geq 0.476$ and $N \geq 22$, the equilibrium $C U$ structure under Article XXIV is strictly more symmetric than without it.

increase in $N$ affects the shape of the CET and thus the way in which Article XXIV binds. We know that for $\gamma \leq \hat{\gamma}(N)$, all CUs are constrained by Article XXIV, but as $N$ increases, the small CU becomes more constrained than the large one as $k^{*} / N \rightarrow 0$ (the maximum of the function $\tau$ is shifting to the left).

${ }^{19}$ Syropoulos (1999) obtains a similar result in a very different setting. He considers CU formation in a three-country model with perfect competition and studies the equilibrium outcome of CU formation in a different parameter space: his parameter of interest is countries comparative advantage and he shows that under Article XXIV, free trade may be reached for a larger range of this parameter. In our case, we have an oligopolistic model of international trade among $\mathrm{N}$ countries and our parameter of interest to determine whether the equilibrium outcome will or not be free trade is the substitution index between goods (or the total number of countries in the world). What our models have in common is that we both find that Article XXIV makes free trade the equilibrium outcome for a wider range of parameters. 


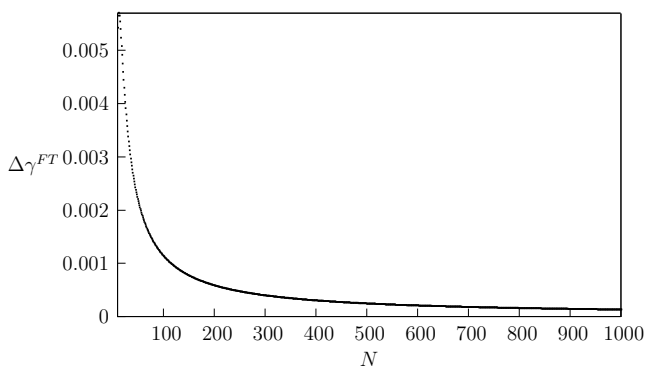

Figure 5: Difference in the free trade threshold substitution index: $\Delta \gamma^{F T}=\gamma_{c}^{F T}-\gamma_{u}^{F T}$.

For higher values of $\gamma$, the large $\mathrm{CU}$ is less constrained than the small $\mathrm{CU}$ (or not at all if the Article XXIV constraint does not bind on the large union which is the case for $\gamma \geq \hat{\gamma}(N)$ with $\hat{\gamma}(N)<0.476$ ) and so the second effect from Proposition 5 dominates (or is the only present). Result 4 refines the analytic result derived in Proposition 6. It is illustrated in Figure 6 which shows again the equilibrium size of the large bloc $k_{L}^{\text {opt }}$ with and without Article XXIV, but this time for the whole range of $\gamma$.

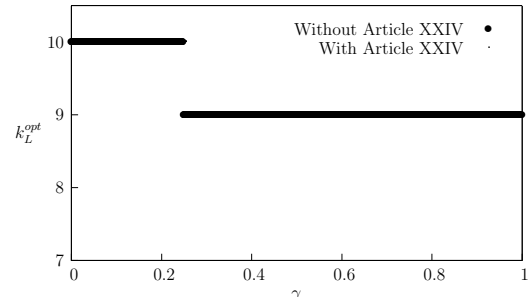

(a) $N=10$

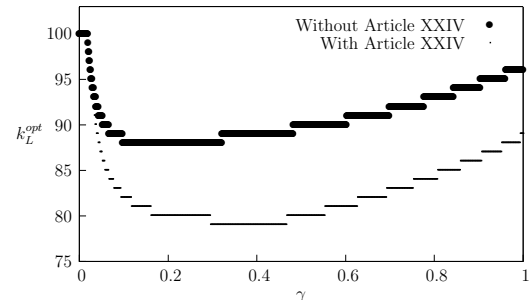

(b) $N=100$

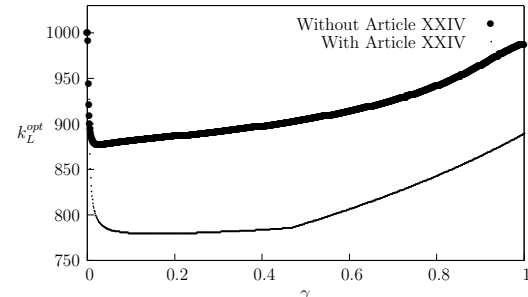

(c) $N=1000$

Figure 6: Size of the large bloc in the equilibrium two CU structure for all $\gamma$.

\subsection{Article XXIV and world welfare}

Finally, we are interested in determining the impact of Article XXIV on world welfare. We know from Proposition 2, that for a given CU structure, by reducing barriers to trade, Article XXIV increases world welfare. However, Proposition 5 tells us that Article XXIV affects the incentives of countries to form CUs, and Proposition 6 and our numerical analysis show that, indeed, Article XXIV affects the equilibrium CU structure. Thus Article XXIV not only reduces barriers to trade, but it also has a composition effect on the equilibrium $\mathrm{CU}$ structure. The total effect on world welfare of Article XXIV depends on how the equilibrium CU structure is affected.

Proposition 7. In an equilibrium $C U$ structure with two $C U s$, when Article XXIV leads to a more asymmetric equilibrium $C U$ structure (or leaves the $C U$ structure unchanged), 
it unambiguously increases world welfare. When Article XXIV leads to a more symmetric equilibrium $C U$ structure, its effect on world welfare is ambiguous.

Proof. Follows from Propositions 2, 3 and 4.

The total effect of Article XXIV on world welfare can be decomposed into two effects: 1) the effect of imposing Article XXIV keeping the CU structure fixed, and 2) the effect of the change in the equilibrium CU structure under Article XXIV. From Proposition 2, we know that the first effect is positive: Article XXIV increases world welfare for a given CU structure. From Proposition 3, we know that, when Article XXIV binds at least on the small union, an increase in the asymmetry between the CUs increases world welfare. (Proposition 4 tells us that, in an equilibrium CU structure with two unions, the small union is always bound by Article XXIV.) Hence when Article XXIV leads to a more asymmetric equilibrium CU structure, the two effects of Article XXIV work in the same direction, and Article XXIV increases world welfare. When Article XXIV leads to a more symmetric equilibrium CU structure, the two effects work in opposite directions, and the effect of Article XXIV is ambiguous.

Evaluating world welfare (9) at the equilibrium CU structures obtained in our numerical analysis with and without Article XXIV confirms that, for low values of $\gamma$, when Article XXIV makes the equilibrium CU structure more asymmetric, world welfare unambiguously increases. On the other hand, for higher values of $\gamma$, when Article XXIV makes the equilibrium CU structure more symmetric, either effect of Article XXIV can dominate and, for a wide range of parameters, world welfare may actually fall. This is particularly important in light of our earlier result that, for a given CU structure, Article XXIV must increase world welfare.

Result 5. When Article XXIV leads to a more symmetric CU structure, world welfare falls for a wide range of parameters.

This result is illustrated in Figure 7, which shows, for $N=30$, how the effect of Article XXIV on world welfare relates to the change in equilibrium CU structures, for different values of gamma. Recall that the equilibrium consists either of one or two asymmetric blocs. Figure 7 (a) shows $k_{L}^{o p t}$, the equilibrium size of the large bloc, with and without Article XXIV, as a function of $\gamma$ when $\gamma$ is low. Figure $7(\mathrm{~b})$ shows $k_{L}^{\text {opt }}$ for the full range $\gamma \in[0,1]$. Figures $7(\mathrm{c})$ and $7(\mathrm{~d})$ show $\Delta k_{L}^{o p t}$, the difference in the equilibrium size of the large bloc with and without Article XXIV, for the respective ranges of $\gamma$. Notice again from Figures $7(\mathrm{a})$ and $7(\mathrm{c})$ that, for low $\gamma(\gamma \leq 0.085616)$, the equilibrium $\mathrm{CU}$ structure is weakly more asymmetric with Article XXIV (the size of the large bloc is larger and $\Delta k_{L}^{o p t} \geq 0$ ), and free trade is reached for a slightly broader range of parameters than without the Article XXIV constraint. For higher values of $\gamma$, as shown in Figures $7(\mathrm{~b})$ and $7(\mathrm{~d})$, the equilibrium $\mathrm{CU}$ structure with Article 


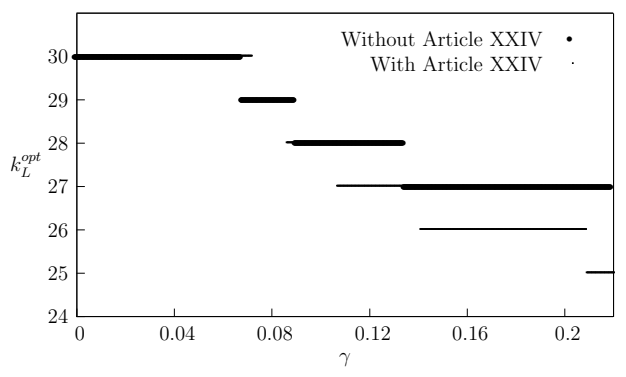

(a) $k_{L}^{\text {opt }}$ for $0 \leq \gamma \leq 0.22$

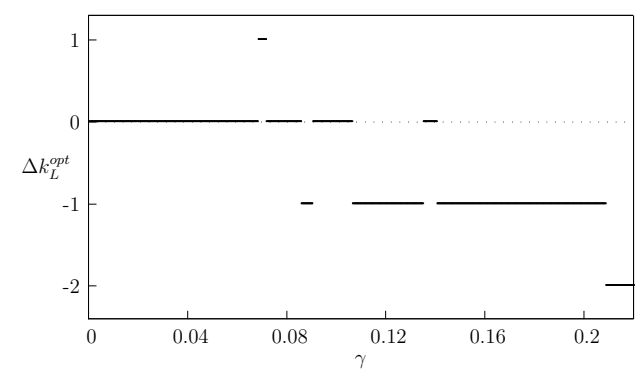

(c) $\Delta k_{L}^{o p t}=k_{L c}^{o p t}-k_{L u}^{o p t}$ for $0 \leq \gamma \leq 0.22$

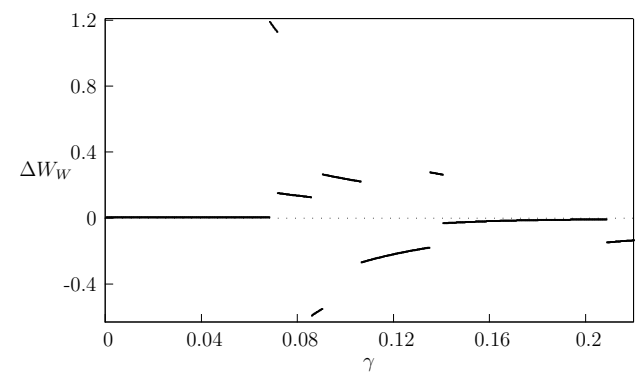

(e) $\Delta W_{W}=W_{W c}-W_{W u}$ for $0 \leq \gamma \leq 0.22$

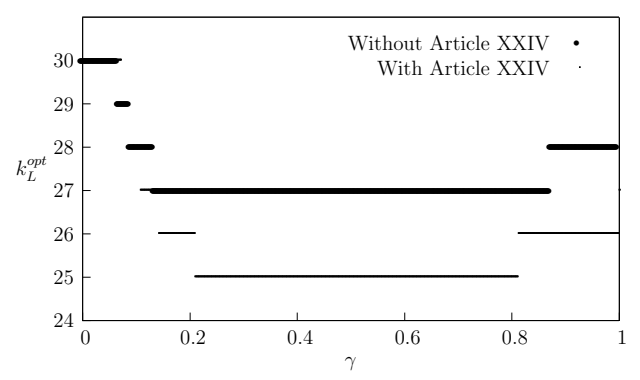

(b) $k_{L}^{o p t}$ for $0 \leq \gamma \leq 1$

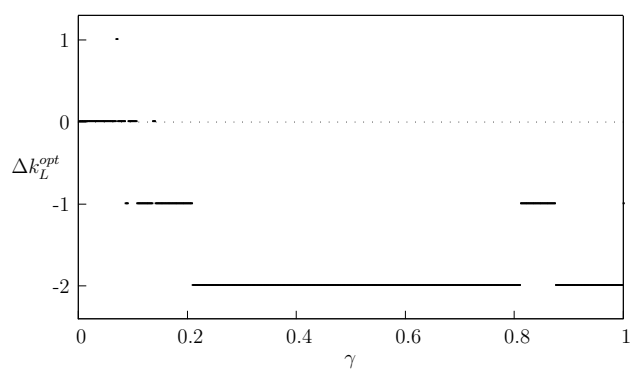

(d) $\Delta k_{L}^{o p t}=k_{L c}^{o p t}-k_{L u}^{o p t}$ for $0 \leq \gamma \leq 1$

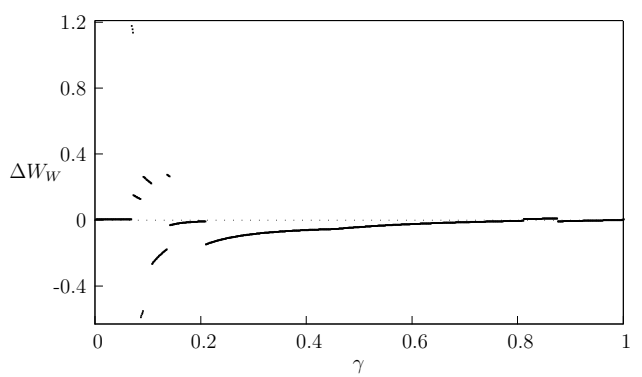

(f) $\Delta W_{W}=W_{W c}-W_{W u}$ for $0 \leq \gamma \leq 1$

Figure 7: Equilibrium size of the large bloc, difference in the equilibrium size of the large bloc and difference in world welfare with and without Article XXIV as a function of $\gamma$ for $N=30$.

XXIV is weakly more symmetric $\left(\Delta k_{L}^{o p t} \leq 0\right) .{ }^{20}$ Figures $7(\mathrm{e})$ and $7(\mathrm{f})$ show the difference in world welfare with and without the Article XXIV constraint. When the equilibrium structure is the same in both cases, the large bloc is of the same size in Figures $7(\mathrm{a})$ and $7(\mathrm{~b}), \Delta k_{L}^{\text {opt }}=0$ in Figures $7(\mathrm{c})$ and $7(\mathrm{~d})$, and world welfare is improved under Article XXIV, because, as we showed in Proposition 2, Article XXIV increases world welfare for a given $\mathrm{CU}$ structure. When the equilibrium structure is strictly more asymmetric under Article XXIV (case when free trade is reached under Article XXIV, but not without it for $\gamma_{u}^{F T}=0.068305<\gamma \leq \gamma_{c}^{F T}=0.071671$ ), there is a significant improvement in world welfare. But when the equilibrium structure is more symmetric under Article XXIV, the large bloc is smaller in Figures 7(a) and 7(b), the difference in the equilibrium size is negative in Figures $7(\mathrm{c})$ and $7(\mathrm{~d})$, and world welfare may be lower. For the case of $N=30$ considered here, world

\footnotetext{
${ }^{20}$ The structure is weakly more symmetric for $\gamma \geq 0.085617$. It becomes strictly more symmetric for $\gamma \geq 0.140462$.
} 
welfare is actually lower every time when the CU structure is strictly more symmetric with the exception of $\gamma \in[0.810577,0.87454]$ and $\gamma \in[0.998993,1]$ where the welfare increasing effect coming from the reduction in trade barriers dominates. ${ }^{21}$ The reduction of world welfare by Article XXIV is the crucial possibility highlighted in this paper.

\section{Conclusion}

This paper has examined the effect of the GATT/WTO's Article XXIV on CU formation, the equilibrium CU structure, the welfare of individual countries and the welfare of the world as a whole. We introduced an Article XXIV constraint into the model of Yi (1996), which formed our benchmark. In this model, CUs form through a coalition formation game: governments decide sequentially on CU membership to maximize their country's welfare. The equilibrium CU structure consists typically of two CUs. The Article XXIV constraint essentially prevents a CU from raising its CET. Its effect depends on which equilibrium $\mathrm{CU}$ is bound by it. When the first CU to form is bound by Article XXIV, it would want to accept more members, because Article XXIV sets a bound on foreign rent extraction and thus makes the benefits from freer trade relatively larger. On the other hand, when the second bloc is constrained by Article XXIV, the first bloc would want to accept fewer members because the welfare loss that the second bloc can inflict on the first bloc is smaller. Thus Article XXIV may make the equilibrium CU structure more or less symmetric depending on which of these two effects dominates. When goods are independent, the first larger bloc is more constrained by Article XXIV, the first effect dominates and the equilibrium CU structure is more asymmetric. A consequence of this is that the range of $\gamma$ for which free trade arises is widened under Article XXIV, making free trade more likely. When goods are more substitutable, the second smaller bloc is more constrained by Article XXIV (or it is the only one to be constrained), the second effect dominates and the equilibrium CU structure is more symmetric. The change in the equilibrium CU structure has important consequences for world welfare as an increase in the symmetry leads to a larger number of varieties being subject to the tariff distortion as they pass between CUs; hence Article XXIV may indeed be bad for world welfare.

Inevitably, the theoretical framework developed here simplifies the situation in a number of key respects. In future work, it would be useful to check the robustness of our results to alternative economic and policy-making environments. To check robustness to alternative economic environments, one could begin by examining the introduction of an Article XXIV constraint to other models of CU formation, such as that of Bond and Syropoulos (1996). These authors study CU formation in an endowment economy with C.E.S. preferences which in all other respects is the same as ours. A key difference between the behavior of their model

\footnotetext{
${ }^{21}$ Note that world welfare appears here to be a discontinuous function of $\gamma$ because of the integer constraint on the CU structure.
} 
and ours is that in their model the CET is monotonically increasing in CU size while in ours, as we have seen, it is non-monotonic. So while in the equilibrium CU structure of our model the Article XXIV constraint may bind only on the small CU, in theirs it would have to bind on both simultaneously. Further analysis is needed to determine which of the effects examined in this paper would dominate, but we conjecture that the monotonic feature of the CET in their model would rule out the reduced asymmetry of CUs under Article XXIV that drives a reduction of world welfare in ours.

To check the robustness of our results to alternative policy-making environments, a useful starting point would be to follow recent research on trade agreements and regionalism where tariffs are used for political or redistributive purposes. ${ }^{22}$ Such considerations could be incorporated in the model of the present paper by putting a higher weight on producers' profits. It seems likely that the basic insights of the present paper about the application of Article XXIV would remain robust to the inclusion of distributional/political concerns of the government.

Since our paper suggests that Article XXIV may worsen world welfare, the question naturally arises as to what an appropriate revision of Article XXIV would be. A followup paper by Mrázová (2010) examines this question and determines by how much it is necessary to reduce the CET of a $\mathrm{CU}$ in this framework to eliminate the harmful effects of CU formation.

While the analysis that we have undertaken reveals a surprising implication of Article XXIV, it does not go on to consider the effects of Article XXIV on multilateral liberalization. Bhagwati (2008) has suggested that there are now so many blocs in existence, and this number is increasing, that this undermines negotiations directed at further liberalization of the WTO. Baldwin (2006) argues the opposite. Dinopoulos and Syropoulos (2008) argue that Article XXIV may lessen the impediments to multilateralism created by the existence of CUs, because it reduces the gains from $\mathrm{CU}$ formation, but alternatively may prevent the progression from regionalism to multilateralism because it makes regionalism more palatable to some parties. An important open question for further research is how the composition effect of Article XXIV that we have identified operates in a dynamic setting.

\footnotetext{
${ }^{22}$ In addition to Ornelas (2005a,b), see for example Krishna (1998), Grossman and Helpman (1995) and Maggi and Rodriguez-Clare (1998).
} 


\section{A Appendix}

For all the derivations, unless otherwise stated, we assume that the parameters of the model lie within the relevant ranges for the analysis, namely $\gamma \in[0,1], N>1$ and $k \in[1, N]$.

\section{Proof of Proposition 1.}

$$
\frac{\partial \tau(k)}{\partial k}=\frac{\gamma \Gamma(0)}{D(k)^{2}}\left\{\Gamma(0) \Gamma(N)[\Gamma(0)+1]-\Gamma(2 k)^{2}\right\} \geq 0 \text { if and only if } k \leq k^{*} \text { given by }(4)
$$

So $\tau(k)$ is a continuous, initially increasing and then decreasing function of $k$ with a maximum at $k^{*}>0$. Note that $\tau(0)<\tau(1)$ for $\gamma>0$ (for $\gamma=0, \tau(k)$ is a constant function) and that $\lim _{k \rightarrow+\infty} \tau(k)=0<\tau(1)$ and so using the intermediate value theorem, we know that the second degree polynomial equation $\tau(k)=\tau(1)$ has two positive roots: a trivial root $k=1$ and another strictly positive root $k^{* *}$. If $k^{*}=1,1$ is a double root (and $k^{* *}=1$ ), if $k^{*} \neq 1$, $k^{* *}$ is different from 1 . Factorizing the equation

$$
\tau(k)-\tau(1)=0 \Leftrightarrow(k-1) \gamma\{\Gamma(0) \Gamma(N)[\Gamma(0)+1]-\Gamma(0) \Gamma(2)-2 \gamma \Gamma(2) k\}=0
$$

yields $k^{* *}$ given by (5). When $k^{*} \leq 1$, we have $k^{* *} \leq 1$. The CET is a monotonically decreasing function on the relevant range $k \in[1, N]$, and thus the Article XXIV constraint does not bind and we have for any $k \in(1, N], k>k^{* *}$ and $\tau_{c}(k)=\tau(k)$. When $k^{*}>1$, we have $k^{* *}>1$. Article XXIV binds for $1 \leq k \leq k^{* *}$. It imposes $\tau_{c}(k)=\tau(1)$ for $1 \leq k \leq k^{* *}$ and $\tau_{c}(k)=\tau(k)$ for $k>k^{* *}$. See the online Appendix for a detailed study of $k^{*}$ and $k^{* *}$.

Proof of Lemma 1. Differentiating $q_{O}(k)$ given by (6) with respect to $k$ yields

$$
\frac{d q_{O}(k)}{d k}= \begin{cases}-\frac{\gamma \tau(1)}{\Gamma(0) \Gamma(N)}<0 & \text { for } 1 \leq k \leq k^{* *} \\ -\frac{\gamma}{D(k)^{2}}\left\{[2(2-\gamma)+1+4 k \gamma](2-\gamma)^{2}+2(1-\gamma) k^{2} \gamma^{2}\right\}<0 & \text { for } k^{* *}<k<N\end{cases}
$$

Note that $\Gamma(0) \Gamma(N) \frac{d q_{O}(k)}{d k}=-\gamma \tau_{c}(k)-\Gamma(k) \frac{d \tau_{c}(k)}{d k}$. When the Article XXIV constraint binds, $\tau_{c}(k) \leq \tau(k)$, so the first term on the right hand-side is negative, but greater under Article XXIV than without. The second term on the right hand-side is 0 when the Article XXIV constraint binds. For $1 \leq k<k^{*}, \tau(k)$ is an increasing function of $k$, so the second term is negative without Article XXIV. So on the whole, under Article XXIV, the derivative of $q_{O}(k)$ is negative, but greater than without Article XXIV. So $q_{O}(k)$ is decreasing at a slower rate under Article XXIV for $1 \leq k<k^{*}$. For $k=k^{*}$, the second term on the right hand-side becomes also 0 without Article XXIV (from the variations of $\tau(k)$ ). This is the point where the difference in the rate of decrease in $q_{O}(k)$ is the largest between the situations with and without Article XXIV. For $k^{*}<k<k^{* *}$, the second term on the right hand-side becomes positive and so the difference in the rates of decrease starts to diminish until it disappears at $k^{* *}$. 
Proof of Lemma 2. 1. Consumer surplus: The consumer surplus of a country belonging to a $k$-size $\mathrm{CU}$ is

$$
C S\left[k, \tau_{c}(k)\right]=\frac{\gamma}{2} Q\left[k, \tau_{c}(k)\right]^{2}+\frac{1-\gamma}{2}\left\{k q_{I}\left[k, \tau_{c}(k)\right]^{2}+(N-k) q_{O}\left[k, \tau_{c}(k)\right]^{2}\right\}
$$

The goal of this proof is to determine the sign of the derivative of CS with respect to $k$. Note that

$$
\frac{d}{d k} C S\left[k, \tau_{c}(k)\right]=\left.\frac{\partial C S}{\partial k}\right|_{\tau_{c}(k)}+\frac{\partial C S}{\partial \tau_{c}} \frac{\partial \tau_{c}}{\partial k}
$$

We proceed in three steps and sign each of the three terms of the derivative separately. We already know from the properties of $\tau_{c}(k)$ that $\frac{\partial \tau_{c}}{\partial k} \leq 0$. Furthermore, making use of (6) and (7), partial differentiation of (10) with respect to $\tau_{c}$ yields

$$
\frac{\partial C S}{\partial \tau_{c}}=\frac{(N-k)}{\Gamma(0)^{2} \Gamma(N)^{2}}\left\{-\Gamma(0)^{2}(1-\gamma+\gamma N)+\left[D(k)-2 \Gamma(k)^{2}\right] \tau_{c}\right\}
$$

As $D(k)-2 \Gamma(k)^{2}=\gamma \Gamma(0)(N-k)+(1-\gamma) \Gamma(N) \Gamma(k)>0$, the partial derivative of consumer surplus is a linear increasing function of the tariff (it is negative for $\tau=0$ ). Call $\tau_{C S m i n}$ the tariff at which the partial derivative of consumer surplus is zero (and consumer surplus is minimum): $\tau_{C \text { Smin }}=\frac{\Gamma(0)^{2}(1-\gamma+\gamma N)}{D(k)-2 \Gamma(k)^{2}}$. The partial derivative of consumer surplus is thus negative for any tariff smaller than $\tau_{C S m i n}$. An easy factorization shows that the Nash optimal tariff $\tau(k)$ is smaller than $\tau_{C \text { Smin }}$ :

$$
\tau_{C \text { Smin }}-\tau(k)=\frac{\Gamma(0)[\Gamma(0) \Gamma(N) \Psi(k)(1-\gamma+\gamma N)+\Gamma(2 k) \Gamma(N) \gamma k]}{D(k)\left[D(k)-2 \Gamma(k)^{2}\right]}>0
$$

As $\tau_{c}(k) \leq \tau(k), \frac{\partial C S}{\partial \tau_{c}} \leq 0$. Moreover, partial differentiation of (10) with respect to $k$ yields

$$
\left.\frac{\partial C S}{\partial k}\right|_{\tau_{c}(k)}=\frac{\tau_{c}}{\Gamma(0)^{2} \Gamma(N)^{2}} \underbrace{\left\{\Gamma(0)^{2}(1-\gamma+\gamma N)-\left[D(k)-2 \Gamma(k)^{2}\right] \tau_{c}\right\}}_{\geq 0 \text { for } \tau_{c} \leq \tau_{C \operatorname{Sin}}}+\underbrace{\frac{\tau_{c}^{2}(1-\gamma)}{2 \Gamma(0)^{2}}}_{\geq 0} \geq 0
$$

Hence the result $\frac{d}{d k} C S\left[k, \tau_{c}(k)\right]=\underbrace{\left.\frac{\partial C S}{\partial k}\right|_{\tau_{c}(k)}}_{\geq 0}+\underbrace{\frac{\partial C S}{\partial \tau_{c}}}_{\leq 0} \underbrace{\frac{\partial \tau_{c}}{\partial k}}_{\leq 0} \geq 0$.

3. Home firm's export profits in new members' markets: From (6) we immediately see that $q_{I}(k) \geq q_{O}\left(k^{\prime}\right)$ for any $k, k^{\prime} \in[1, N]$.

Home firm's domestic profits and export profits in existing members' markets:

$$
\frac{d q_{I}(k)}{d k}=\frac{1}{\Gamma(0) \Gamma(N)}\left\{[\Gamma(N)-\Gamma(k)] \frac{d \tau_{c}(k)}{d k}-\gamma \tau_{c}(k)\right\} \leq 0
$$

given that $\frac{d \tau_{c}(k)}{d k} \leq 0$ and $\tau_{c}(k) \geq 0$. 
Proof of Lemma 3. Suppose that CUs of size $k$ and $s$ merge. To prove that, under Article XXIV, the merger of these CUs increases the aggregate welfare of member countries, we need to distinguish three cases. First, the case where neither of the two initial CUs nor the after-merger CU are bound by Article XXIV. This case was proved by Yi (1996) (see Yi (1996), Appendix B, pages 172-175). ${ }^{23}$ Second, the case where both the two initial CUs and the after-merger CU are bound by Article XXIV. This proof proceeds along similar lines as Yi's (1996) proof of the unconstrained case with the difference that the CET of the merging CUs is kept constant by the binding Article XXIV at $\tau_{c}(k)=\tau(1)$. For details see the online Appendix. Third, we need to consider the case where the Article XXIV constraint is binding for (at least one of) the initial CUs but not for the after-merger CU. ${ }^{24}$ Consider the tariffs of the CUs not involved in the merger as given (could be constrained or unconstrained). Let the subscript $u$ denote an unconstrained $\mathrm{CU}$ and the subscript $c$ a constrained CU. By Yi's proof, we have $(k+s) W_{u}(k+s) \geq k W_{u}(k)+s W_{u}(s)$. Now, given the tariffs of the CUs not involved in this merger, the CUs of size- $k$ and size- $s$ involved in this merger are better off when unconstrained compared to the constrained situation $k W_{u}(k)+s W_{u}(s) \geq k W_{c}(k)+s W_{c}(s)$. So, we have $(k+s) W_{u}(k+s) \geq k W_{c}(k)+s W_{c}(s)$.

Proof of Proposition 2. Consider $C=\left\{k_{1}, k_{2}, \ldots, k_{m}\right\}$, a CU structure where $k_{i}$ is the size of the $i^{\text {th }} \mathrm{CU}$. Using (6), (7), (8), the differentiation of world welfare (9) with respect to the CET of the $i^{\text {th }} \mathrm{CU} \tau_{i}$ yields

$$
\frac{d W_{W}}{d \tau_{i}}=k_{i} \frac{d N S_{i}}{d \tau_{i}}=-\frac{k_{i}\left(N-k_{i}\right)}{\Gamma(0)^{2} \Gamma(N)^{2}}\left\{\Gamma(0)^{2}+\left[D\left(k_{i}\right)-2 \Gamma\left(k_{i}\right)^{2}\right] \tau_{i}\right\} \leq 0
$$

As $D\left(k_{i}\right)-2 \Gamma\left(k_{i}\right)^{2}=\gamma \Gamma(0)\left(N-k_{i}\right)+(1-\gamma) \Gamma(N) \Gamma\left(k_{i}\right) \geq 0$, we have $\frac{d W_{W}}{d \tau_{i}} \leq 0$ for any $\tau_{i} \geq 0$. So for a given CU structure, world welfare is a decreasing function of any CET of any union. The Article XXIV either lowers CETs when it binds or leaves them unaffected when it does not bind, and thus weakly increases world welfare.

Proof of Proposition 3. Consider a CU structure $C=\left\{k_{1}, k_{2}, \ldots, k_{m}\right\}$. Without loss of generality, assume that the first CU (of size $k_{1}$ ) is expanding by accepting members from the last $\mathrm{CU}$ (of size $k_{m}$ ). We want to see the impact on world welfare of an increase in the asymmetry between these two CUs, so we assume $k_{1} \geq k_{m}$. The large CU is imposing a CET $\tau_{1}$, the small $\mathrm{CU}$ is imposing $\tau_{m}$. The sub-structure $\left\{k_{2}, \ldots, k_{m-1}\right\}$, which stays constant, will be irrelevant for the changes in world welfare and the only thing that will matter will be the sum of the sizes of the other unions so let's define $\tilde{k} \equiv k_{2}+\ldots+k_{m-1}$. We can then re-express the size of the last CU $k_{m}=N-\tilde{k}-k_{1}$. We want to determine the sign of

\footnotetext{
${ }^{23}$ Note that this proof is valid for a group of CUs for whom the Article XXIV constraint does not bind even though it might bind on other CUs not involved in the merger.

${ }^{24}$ From the properties of the CET we know that the converse cannot occur.
} 
$\frac{d W_{W}\left(k_{1}, k_{2}, \ldots, N-\tilde{k}-k_{1}\right)}{d k_{1}}$. The total derivative can be decomposed as follows

$$
\frac{d W_{W}}{d k_{1}}=\left.\frac{\partial W_{W}}{\partial k_{1}}\right|_{\left(\tau_{1}, \tau_{m}\right)}+\underbrace{\frac{\partial W_{W}}{\partial \tau_{1}}}_{\leq 0} \underbrace{\frac{\partial \tau_{1}}{\partial k_{1}}}_{\leq 0}+\frac{\partial W_{W}}{\partial \tau_{m}} \underbrace{\frac{\partial \tau_{m}}{\partial k_{1}}}_{=0}
$$

We assume that Article XXIV binds at least on the small union involved in the transformation, and so we have $\tau_{m}=\tau_{c}\left(N-\tilde{k}-k_{1}\right)=\tau(1)$ and hence $\frac{\partial \tau_{m}}{\partial k_{1}}=0$. Furthermore, with Article XXIV in place, we know that $\tau_{1}=\tau_{c}\left(k_{1}\right)$ is a non-increasing function of $k_{1}$ and so we have $\frac{\partial \tau_{1}}{\partial k_{1}} \leq 0$. From the proof of Proposition 2 above we also have $\frac{\partial W_{W}}{\partial \tau_{1}} \leq 0$. The remainder of this proof shows that $\left.\frac{\partial W_{W}}{\partial k_{1}}\right|_{\left(\tau_{1}, \tau_{m}\right)} \geq 0$ when $k_{1}+k_{m} \geq \frac{2}{3} N$. Making use of $(6),(7),(8)$, partial differentiation of world welfare (9) with respect $k_{1}$ yields

$$
\begin{gathered}
\left.\frac{\partial W_{W}}{\partial k_{1}}\right|_{\left(\tau_{1}, \tau_{m}\right)}=\frac{1}{2 \Gamma(0)^{2} \Gamma(N)^{2}}\left\{2 \Gamma(0)^{2}\left[\left(2 k_{1}-N\right) \tau_{1}+\tilde{k} \tau_{m}+\left(2 k_{1}+\tilde{k}-N\right) \tau_{m}\right]\right. \\
\left.+\alpha\left(k_{1}, N, \gamma\right) \tau_{1}^{2}+\beta\left(\tilde{k}+k_{1}, N, \gamma\right) \tau_{m}^{2}\right\}
\end{gathered}
$$

where

$$
\begin{aligned}
\alpha(k, N, \gamma) \equiv & -3 \gamma^{2}[\Gamma(N)-N] k^{2} \\
& +2\left[-\gamma^{2}(1-\gamma) N^{2}+2 \gamma \Gamma(0) N+\Gamma(0)^{2}(1-\gamma)\right] k \\
& -\Gamma(0)^{2}(1-\gamma+\gamma N) N \\
\beta(k, N, \gamma) \equiv & 3 \gamma^{2}[\Gamma(N)-N] k^{2} \\
& +2\left[2 \gamma^{2}(1-\gamma) N^{2}+\gamma \Gamma(0)(2-3 \gamma) N+\Gamma(0)^{2}(1-\gamma)\right] k \\
& -(1-\gamma) \Gamma(N)^{2} N
\end{aligned}
$$

Recall from the study of the Article XXIV constraint that Article XXIV can either bind on both the small and the large union $\left(\tau_{1}=\tau_{m}=\tau(1)\right)$ or it can bind on the small union only $\left(\tau_{m}=\tau(1)\right.$ and $\left.\tau_{1}=\tau\left(k_{1}\right) \leq \tau(1)\right)$. Article XXIV can never bind on the large union and not bind on the small union. To sign (14) we thus need to distinguish two cases:

1) Article XXIV binds on both the small and the large CUs $\left(\tau_{1}=\tau_{m}=\tau(1)\right)$ : When both unions are constrained, equation (14) simplifies to

$$
\begin{aligned}
\left.\frac{\partial W_{W}}{\partial k_{1}}\right|_{\left(\tau_{1}, \tau_{m}\right)}= & \frac{\left(k_{1}-k_{m}\right) \tau(1)}{2 \Gamma(0)^{2} \Gamma(N)^{2}}\left\{4 \Gamma(0)^{2}+\left[\Gamma(0)^{2}(1-\gamma+\gamma N)+(1-\gamma) \Gamma(N)^{2}\right] \tau(1)\right. \\
& \left.-\tilde{k} 3 \gamma^{2}[N-\Gamma(N)] \tau(1)\right\}
\end{aligned}
$$

The first line of (15) is positive. The second line can be either positive or negative depending on the parameters $\gamma$ and $N: N-\Gamma(N) \leq 0 \Leftrightarrow \gamma \geq \bar{\gamma}(N) \equiv \frac{N-2}{N-1}$. Hence (15) is unambiguously positive for $\gamma \geq \bar{\gamma}(N)$. For $\gamma=0$, (15) further simplifies and it is also unambiguously 
positive: $\left.\frac{\partial W_{W}}{\partial k_{1}}\right|_{\left(\tau_{1}, \tau_{m}\right)}=\frac{\left(k_{1}-k_{m}\right) \tau(1)}{4}[2+\tau(1)] \geq 0$.

For $0<\gamma<\bar{\gamma}(N)$, the second line of (15) is negative. The whole expression (15) is positive provided that $\tilde{k}$ is sufficiently small. In other words, the two CUs involved in the change considered have to represent a sufficient proportion of countries in the world: we have to have $k_{1}+k_{m}=N-\tilde{k} \geq \bar{k}_{c} \equiv \max \left(0, \hat{k}_{c}\right)$ where

$$
\begin{aligned}
\hat{k}_{c} & \equiv N-\frac{4 \Gamma(0)^{2}+\left[\Gamma(0)^{2}(1-\gamma+\gamma N)+(1-\gamma) \Gamma(N)^{2}\right] \tau(1)}{3 \gamma^{2}[N-\Gamma(N)] \tau(1)} \\
& =\frac{2\left\{(1-\gamma) \gamma^{2} \tau(1) N^{2}-2 \Gamma(0) \gamma \tau(1) N-\Gamma(0)^{2}[2+(1-\gamma) \tau(1)]\right\}}{3\left[(1-\gamma) \gamma^{2} \tau(1) N-\Gamma(0) \gamma^{2} \tau(1)\right]} \leq \frac{2}{3} N
\end{aligned}
$$

2) Article XXIV binds on the small union only $\left(\tau_{1}=\tau\left(k_{1}\right) \leq \tau(1)=\tau_{m}\right)$ : With $\tau_{m} \geq \tau_{1}$, we have $\left(2 k_{1}-N\right) \tau_{1}+\tilde{k} \tau_{m}+\left(2 k_{1}+\tilde{k}-N\right) \tau_{m} \geq\left(2 k_{1}-N\right) \tau_{1}+\tilde{k} \tau_{1}+\left(2 k_{1}+\tilde{k}-N\right) \tau_{m}=$ $\left(k_{1}-k_{m}\right)\left(\tau_{1}+\tau_{m}\right) \geq 0$. And so the first line of (14) is unambiguously positive. We now need to sign the expressions $\alpha$ and $\beta$. As we show by successive differentiation in the online Appendix, $\beta(k, N, \gamma)$ is positive for $N \geq 6$ when Article XXIV binds on the small union, but not on the large one. $\alpha(k, N, \gamma)$ can be either positive or negative depending on the parameters. We can therefore distinguish two cases: When $\alpha(k, N, \gamma) \geq 0$, we can immediately conclude that (14) is positive. When $\alpha(k, N, \gamma)<0$, we can note that

$$
\alpha\left(k_{1}, N, \gamma\right) \tau_{1}^{2}+\beta\left(\tilde{k}+k_{1}, N, \gamma\right) \tau_{m}^{2} \geq\left[\alpha\left(k_{1}, N, \gamma\right)+\beta\left(\tilde{k}+k_{1}, N, \gamma\right)\right] \tau_{m}^{2}
$$

and

$$
\begin{aligned}
\left.\frac{\partial W_{W}}{\partial k_{1}}\right|_{\left(\tau_{1}, \tau_{m}\right)} \geq & \frac{\left(k_{1}-k_{m}\right)}{2 \Gamma(0)^{2} \Gamma(N)^{2}}\left\{2 \Gamma(0)^{2}\left(\tau_{1}+\tau_{m}\right)+\left[\Gamma(0)^{2}(1-\gamma+\gamma N)+(1-\gamma) \Gamma(N)^{2}\right] \tau_{m}^{2}\right. \\
& \left.-\tilde{k} 3 \gamma^{2}[N-\Gamma(N)] \tau_{m}^{2}\right\}
\end{aligned}
$$

As in (15) in the constrained case 1), the first line of (16) is positive. The second line can be either positive or negative depending on the parameters $\gamma$ and $N$. The second line is positive for $\gamma \geq \bar{\gamma}(N)$ and for $\gamma=0$, and thus the partial derivative of welfare is positive for these values. For $0<\gamma<\bar{\gamma}(N)$, the second line of (16) is negative. The whole expression (16) is again positive provided that $\tilde{k}$ is sufficiently small. We have to have $k_{1}+k_{m}=N-\tilde{k} \geq \bar{k}_{u} \equiv \max \left(0, \hat{k}_{u}\right)$ where

$$
\begin{aligned}
\hat{k}_{u} & \equiv N-\frac{2 \Gamma(0)^{2}\left(\tau_{1}+\tau_{m}\right)+\left[\Gamma(0)^{2}(1-\gamma+\gamma N)+(1-\gamma) \Gamma(N)^{2}\right] \tau_{m}^{2}}{3 \gamma^{2}[N-\Gamma(N)] \tau_{m}^{2}} \\
& =\frac{2\left\{(1-\gamma) \gamma^{2} \tau_{m}^{2} N^{2}-2 \Gamma(0) \gamma \tau_{m}^{2} N-\Gamma(0)^{2}\left[\tau_{1}+\tau_{m}+(1-\gamma) \tau_{m}^{2}\right]\right\}}{3\left[(1-\gamma) \gamma^{2} \tau_{m}^{2} N-\Gamma(0) \gamma^{2} \tau_{m}^{2}\right]} \leq \frac{2}{3} N
\end{aligned}
$$


And so for $k_{1}+k_{m} \geq \frac{2 N}{3}$, we have unambiguously in both cases 1) and 2)

$$
\frac{d W_{W}}{d k_{1}}=\underbrace{\left.\frac{\partial W_{W}}{\partial k_{1}}\right|_{\left(\tau_{1}, \tau_{m}\right)}}_{\geq 0}+\underbrace{\frac{\partial W_{W}}{\partial \tau_{1}} \underbrace{\frac{\partial \tau_{1}}{\partial k_{1}}}_{\leq 0}}_{\geq 0}+\frac{\partial W_{W}}{\partial \tau_{m}} \underbrace{\frac{\partial \tau_{m}}{\partial k_{1}}}_{=0} \geq 0
$$

Proof of Lemma 7. 1. Smallest CU: The smallest CU must be unique, because, according to Lemma 5, two CUs of the same size would be better off by merging. The last union to form must be the smallest since, by Lemma 5, the smallest CU entails the lowest level of welfare for its members.

2. Second smallest CU: The second smallest CU must be unique, because two symmetric CUs would be better off by merging. Suppose that the second smallest CU has less than $k_{0}$ members. Then the members of this union would be better off by admitting (at least) one more member.

3. Number of equilibrium CUs: The second smallest CU which is the second-to-last to form has at least $k_{0}$ members and all the CUs that form before have strictly more members than this CU. Thus there cannot be more than $I\left(\frac{N}{k_{0}}\right)$ CUs in equilibrium where $I\left(\frac{N}{k_{0}}\right)$ is the next highest integer to $\frac{N}{k_{0}}$. The goal of this proof is to determine a lower bound for $k_{0}$ in order to get an upper bound for the number of equilibrium CUs.

Recall that $k_{0}$ is the largest integer such that, for any $k \leq k_{0}, W(k, C)-W\left(k-1, C^{\prime}\right) \geq 0$. When $\gamma=0$, for any $k$ and $N$ we have $W(k, C)-W\left(k-1, C^{\prime}\right)=\frac{7}{72}>0$ and $k_{0}$ is infinite. There will be only one $\mathrm{CU}$ of size $N$ in equilibrium when $\gamma=0$. When, $\gamma>0$, treating $k$ as continuous, we want to solve for $k_{0}$ such that $W(k, C)-W\left(k-1, C^{\prime}\right)=0$

$$
\Leftrightarrow N S(k)-N S(k-1)-(N-k) q_{O}(k)^{2}+(N-k+1) q_{O}(k-1)^{2}-q_{O}(1)^{2}=0
$$

In order to solve for $k_{0}$, we need to distinguish three cases:

a) $k_{0}$ is such that a CU of size $k_{0}$ is constrained by Article XXIV: If a size- $k_{0}$ $\mathrm{CU}$ is constrained by Article XXIV then a size- $\left(k_{0}-1\right)$ must also be constrained by Article XXIV. In this case, making use of $(6),(7)$ and (8), together with $\tau_{c}(k)=\tau_{c}(k-1)=\tau(1)$, (17) becomes

$$
\frac{\tau(1)}{2 \Gamma(0)^{2} \Gamma(N)^{2}}\left(\omega_{2} k^{2}+\omega_{1} k+\omega_{0}\right)=0
$$

with

$$
\begin{aligned}
& \omega_{2} \equiv 6 \gamma^{2} \tau(1) \geq 0 \\
& \omega_{1} \equiv-2 \gamma\left\{4 \Gamma(0)+\tau(1)\left[(1+\gamma) \gamma N-8+9 \gamma-\gamma^{2}\right]\right\} \leq 0 \\
& \omega_{0} \equiv 2 \Gamma(0) \Gamma(2 N+4)+\tau(1)\left[-(1-\gamma) \gamma^{2} N^{2}-(1-\gamma) \gamma(4+\gamma) N+\Gamma(0)\left(2-11 \gamma+2 \gamma^{2}\right)\right]
\end{aligned}
$$


Equation (18) is a second-degree polynomial equation in $k$. Substituting $\tau(1)$ into the $\omega_{i}$, we can solve (18) for $k_{0}(N, \gamma)$. In the online Appendix, we provide the explicit solution for $k_{0}(N, \gamma)$ and we show that, for $\gamma>0, k_{0}(N, \gamma)$ is a continuous and monotonically decreasing function of $\gamma$. Thus evaluating $k_{0}$ at $\gamma=1$ gives a lower bound for $k_{0}$ :

$$
k_{0}(N, 1)=\frac{1}{18}\left[10 N+28-\sqrt{2\left(14 N^{2}-62 N-49\right)}\right] \geq \frac{5-\sqrt{7}}{9} N
$$

Hence there will be at most four CUs in equilibrium. Furthermore, we can note that $k_{0}(N, 1)>\frac{N}{3}$ for $N \leq 31$ and so for $N \leq 31$ there will be at most three CUs in equilibrium. As $k_{0}$ is a continuous and decreasing function of $\gamma$, with $k_{0}(N, \gamma) \rightarrow+\infty$ when $\gamma \rightarrow 0^{+}$and $k_{0}(N, 1)<\frac{N}{3}$ for $N>31$, there exists a unique $\gamma_{3} \in(0,1)$ for which $k_{0}=\frac{N}{3}$. This $\gamma_{3}$ is a complicated function of $N$, but $\underline{\gamma_{3}}=\frac{1}{2}(13-\sqrt{129}) \approx 0.821092$ is a lower bound for $\gamma_{3}$, because $k_{0}\left(N, \underline{\gamma_{3}}\right) \geq \frac{N}{3}$ (with equality for $N=+\infty$ ). Hence we also know that for $N>31$ and $\gamma \in\left[0, \frac{1}{2}(13-\sqrt{129})\right]$ there will be at most three CUs in equilibrium.

b) $k_{0}$ is such that a CU of size $k_{0}$ is not constrained by Article XXIV, but a CU of size $k_{0}-1$ is constrained by Article XXIV: If this case occurs, we have $W_{u}(k, C)-W_{c}\left(k-1, C^{\prime}\right) \geq W_{c}(k, C)-W_{c}\left(k-1, C^{\prime}\right)$ and so the derivations from case a) above also provide a lower bound for $k_{0}$ is this case.

c) $k_{0}$ is such that neither a CU of size $k_{0}$ nor of size $k_{0}-1$ are constrained by Article XXIV: This case corresponds to the case without the Article XXIV constraint analyzed by Yi (1996) who shows that there will be at most three CUs in equilibrium.

Proof of Proposition 4. We assume that the equilibrium CU structure consists of at most two blocs: a bloc of size $k$ which forms first and a bloc of size $N-k$. From Lemma 7 we know that the two blocs will necessarily be asymmetric with the larger bloc forming first and so we have $k>N-k$. (Note that we allow the small bloc to be empty $(k=N)$ in which case there is only one bloc in equilibrium. $)^{25}$

To determine which bloc will be constrained and when, we need to determine the equilibrium size of the two blocs. The large CU (the first bloc to form) is choosing its size $k$ to maximize its welfare knowing that the second bloc will be formed by the remaining countries. The optimization problem is thus

$$
\underset{k}{\operatorname{argmax}} W(k,\{k, N-k\})
$$

To solve this optimization problem, we need to calculate the first derivative of the welfare function of the large $\mathrm{CU} W(k,\{k, N-k\})$ with respect to its size $k$. But the welfare function $W(k,\{k, N-k\})$ changes depending on which of the blocs is constrained. So to

\footnotetext{
${ }^{25}$ From Lemma 7 we know that for $\gamma=0$ there will be only one CU in equilibrium and so Article XXIV will have no hold.
} 
determine the equilibrium size of the two blocs, we need to make assumptions on which bloc is constrained and then we have to check that the obtained equilibrium sizes do not contradict our assumptions. Hence the proof proceeds in three steps. First, we solve for the equilibrium size of the two blocs assuming that they are both constrained and we determine the range of parameters for which the obtained equilibrium sizes are indeed such that the two blocs are constrained. Second, we solve for the equilibrium size of the two blocs assuming that only the small bloc is constrained and we show that, on the remainder of the parameter range, the equilibrium sizes are such that only the small bloc is constrained. Finally, to complete the proof, we solve for the equilibrium size of the two blocs assuming that neither of them is constrained and we show that the equilibrium sizes are such that the small bloc would necessarily be constrained. Hence we can conclude that the case in which neither bloc is constrained never arises in equilibrium with Article XXIV.

1) Both blocs are constrained by Article XXIV (CC): Making use of (6), (7) and (8) with $\tau_{c}(k)=\tau_{c}(N-k)=\tau(1)$, we can calculate the first derivative of the welfare function of the large bloc with respect to its size

$$
\frac{d W_{c c}(k,\{k, N-k\})}{d k}=\frac{2+\gamma}{2 \Gamma(N)^{2} D(1)^{2}}\left[\lambda_{0}(N, \gamma)-2 \gamma \lambda_{1}(N, \gamma) k\right]
$$

with

$$
\begin{aligned}
& \lambda_{0}(N, \gamma) \equiv \Gamma(0)\left(28-20 \gamma+5 \gamma^{2}+\gamma^{3}\right)+4 \gamma\left(30-29 \gamma+13 \gamma^{2}\right) N+\gamma^{2}\left(34-41 \gamma+\gamma^{2}\right) N^{2} \\
& \lambda_{1}(N, \gamma) \equiv 64-60 \gamma+32 \gamma^{2}-\gamma^{3}+\gamma\left(22-27 \gamma+\gamma^{2}\right) N
\end{aligned}
$$

When $\gamma=0$, the derivative is strictly positive and independent of $k: \frac{d W(k,\{k, N-k\})}{d k}=\frac{7}{72}>0$. The optimal size of the large bloc is thus $k_{c c}^{o p t}=N$. When $0<\gamma \leq \gamma_{\frac{N}{2}}, \lambda_{0}(N, \gamma)>0$ and $\lambda_{1}(N, \gamma)>0$ and from setting (19) equal to zero we have

$$
k_{c c}^{o p t}(N, \gamma)=\frac{\lambda_{0}(N, \gamma)}{2 \gamma \lambda_{1}(N, \gamma)}
$$

In the online Appendix we study in detail the properties of $k_{c c}^{o p t}(N, \gamma)$. We show that for any $N$ and $\gamma>0, k_{c c}^{o p t}(N, \gamma) \geq \frac{17}{22} N$. Hence, if the size of the large bloc is $k_{c c}^{o p t}$, we know that the size of the small bloc is smaller than $\frac{5}{22} N<k^{* *}(N, 1)$ and so the small bloc is necessarily constrained by Article XXIV.

Furthermore, we show that $\Delta_{k} \equiv k^{* *}-k_{c c}^{o p t}$ is a continuous, monotonically decreasing function of $\gamma$ for $\gamma \in\left(0, \gamma_{\frac{N}{2}}\right]$. For $N \geq 1$, we have $\Delta_{k}\left(N, \frac{466}{1000}\right)>0$, and for $N \geq 5$, we have $\Delta_{k}\left(N, \frac{476}{1000}\right)<0$. So by the intermediate value theorem, we know that there exists a unique $\hat{\gamma}(N) \in\left(\frac{466}{1000}, \frac{476}{1000}\right)$ such that $\Delta_{k}[N, \hat{\gamma}(N)]=0$. Hence for $\gamma \leq \hat{\gamma}(N)$ we have $k_{c c}^{o p t} \leq k^{* *}$ and for $\gamma>\hat{\gamma}(N)$ we have $k_{c c}^{o p t}>k^{* *}$. Therefore for $\gamma \leq \hat{\gamma}(N)$ both CUs are well constrained by Article XXIV and $k_{c c}^{o p t}$ is the relevant solution for the equilibrium size of the large CU on 
this interval.

2) Only the small bloc is constrained by Article XXIV (UC): Again making use of (6), (7) and (8), but now with the large bloc imposing $\tau_{c}(k)=\tau(k) \leq \tau(1)$ and the small bloc imposing $\tau_{c}(N-k)=\tau(1)$, we can calculate the first derivative of the welfare function of the large bloc with respect to its size. The optimal size of the large CU $k_{u c}^{o p t}$ is given by setting the derivative equal to zero which yields a sixth-degree polynomial equation in $k$. It is hard to find a closed-form solution of this equation, we can however provide a lower bound for $k_{u c}^{o p t}$ by showing that, for $\gamma>\hat{\gamma}(N)$, the derivative of welfare is strictly positive for $k \in\left[N-k^{* *}, \max \left(\frac{78}{100} N, k^{* *}\right)\right]$. We thus have $k_{u c}^{o p t} \geq \max \left(\frac{78}{100} N, k^{* *}\right)$. Hence we know that, for $\gamma>\hat{\gamma}(N)$, the small CU must be smaller than $\frac{22}{100} N$ and, as $\frac{22}{100} N<k^{* *}(N, 1)$, the small union is constrained by Article XXIV. As, $k_{u c}^{o p t} \geq k^{* *}$, the large CU is not constrained.

3) No bloc is constrained by Article XXIV (UU): As a final check, we show that this assumption leads to a contradiction. Making use of (6), (7) and (8), but now with the large bloc imposing $\tau_{c}(k)=\tau(k)$ and the small bloc imposing $\tau_{c}(N-k)=\tau(N-k)$, we again calculate the first derivative of the welfare function of the large bloc with respect to its size. The optimal size of the large $\mathrm{CU} k_{u u}^{o p t}$ is again given by setting this derivative equal to zero which yields an eighth-degree polynomial equation in $k$. By showing that the derivative of welfare is strictly positive for $k \in\left[\frac{N}{2}, \frac{88}{100} N\right]$, we provide a lower bound for $k_{u u}^{o p t}: k_{u u}^{o p t} \geq \frac{88}{100} N$. If the large $\mathrm{CU}$ is larger than $\frac{88}{100} N$, then the small $\mathrm{CU}$ must be smaller than $\frac{12}{100} N$. As $\frac{12}{100} N<k^{* *}(N, 1)$, this leads to a contradiction: a union smaller than $k^{* *}(N, 1)$ is necessarily constrained by Article XXIV. Therefore, in a two-bloc equilibrium, the small bloc is always constrained by Article XXIV.

Proof of Proposition 5. We assume that the equilibrium CU structure consists of at most two blocs: a bloc of size $k$ which forms first and a bloc of size $N-k$. From Lemma 7 we know that the two blocs will necessarily be asymmetric with the larger bloc forming first and so we have $k>N-k$. The aim of this proof is to determine how does the presence of the Article XXIV constraint affect the large CU's choice of its size.

1. Article XXIV binding on the large CU $\rightarrow$ more asymmetry: the goal here is to determine how a change in the CET of the large CU affects the large CU's willingness to accept more or less members, i.e. we want to determine the sign of $\left.\frac{\partial}{\partial \tau_{L}} \frac{\partial W^{L}(k)}{\partial k}\right|_{\tau_{L}=\tau(1), k_{c c}^{\text {opt }}}$ where $\tau_{L}$ is the external tariff imposed by the large union and $W^{L}$ is the welfare of a member country of the large union. We are interested in the sign of this second derivative at the point where the large union is bound by Article XXIV $\tau_{L}=\tau(1)$ (because we want to see the local impact of removing Article XXIV and raising $\tau_{L}$ ) and where the large union has chosen its size optimally $k_{c c}^{o p t}$ (case where both unions are constrained by Article XXIV). 
Making use of (6), (7) and (8), we have

$$
\begin{aligned}
\frac{\partial^{2} W^{L}(k)}{\partial k \partial \tau_{L}}= & \frac{1}{\Gamma(0)^{2} \Gamma(N)^{2}}\left\{6 \gamma \tau_{L} k^{2}\right. \\
& +\left\{\tau_{L}\left[2 \gamma \Gamma(0) \Gamma(N)-6 \gamma^{2} N+4 \gamma \Gamma(0)\right]-4 \gamma \Gamma(0)\right\} k \\
& \left.+\tau_{L}\left\{\Gamma(0) \Gamma(N)[\Gamma(0)-\gamma N]+\gamma^{2} N^{2}+\Gamma(0)^{2}-2 \gamma \Gamma(0) N\right\}+\Gamma(0)[\Gamma(2 N)-2 \Gamma(0)]\right\}
\end{aligned}
$$

As we show in the online Appendix, evaluating (21) at $\tau_{L}=\tau(1)$ and $k=k_{c c}^{o p t}$ given by (20) yields $\left.\frac{\partial}{\partial \tau_{L}} \frac{\partial W^{L}(k)}{\partial k}\right|_{\tau_{L}=\tau(1), k=k_{c c}^{o p t}} \leq 0$ for $\gamma \in[0, \hat{\gamma}(N)]$. So, when Article XXIV is binding on the big bloc, if it could raise its tariff, it would want to accept fewer members.

2. Article XXIV binding on the small CU $\rightarrow$ more symmetry: the goal here is to determine how a change in the CET of the small CU affects the large CU's willingness to accept more or less members, i.e. we want to determine the sign of $\left.\frac{\partial}{\partial \tau_{S}} \frac{\partial W^{L}(k)}{\partial k}\right|_{\tau_{S}=\tau(1), k=k^{\text {opt }}}$ where $\tau_{S}$ is the external tariff imposed by the small union and $W^{L}$ is the welfare of a member country of the large union. Again, we are interested in the sign of this second derivative at the point where the small union is constrained by Article XXIV $\tau_{S}=\tau(1)$ and where the large union has chosen its size optimally. Hence, when the large union is also constrained by Article XXIV $(\gamma \leq \hat{\gamma}(N))$, we want to evaluate the second derivative at $k=k_{c c}^{o p t}$, and, when the large union is not constrained by Article XXIV $(\gamma>\hat{\gamma}(N))$, we want to evaluate the second derivative at $k=k_{u c}^{o p t}$. Making use of (6), (7) and (8)

$$
\frac{\partial}{\partial k} \frac{\partial W^{L}(k)}{\partial \tau_{S}}=\frac{2}{\Gamma(0)^{2} \Gamma(N)^{2}}\left\{\Gamma(0) \Gamma[2(N-k)]-\tau_{S} \Gamma(N-k) \Gamma[3(N-k)]\right\}
$$

As we show in the online Appendix, evaluating (22) at $\tau_{S}=\tau(1)$ and $k=k_{c c}^{\text {opt }}$ given by (20) yields $\left.\frac{\partial}{\partial \tau_{S}} \frac{\partial W^{L}(k)}{\partial k}\right|_{\tau_{S}=\tau(1), k=k_{c c}^{\text {opt }}} \geq 0$ for $\gamma \in[0, \hat{\gamma}(N)]$. For $\gamma>\hat{\gamma}(N)$, we do not have the exact expression for $k_{u c}^{o p t}$, however, from the proof of Proposition 4, we know that $k_{u c}^{o p t} \geq \frac{78}{100} N$. We show that $\left.\frac{\partial}{\partial \tau_{S}} \frac{\partial W^{L}(k)}{\partial k}\right|_{\tau_{S}=\tau(1)} \geq 0$ for any $k \in\left[\frac{78}{100} N, N\right]$.

Proof of Proposition 6. As explained in the the proof of Proposition 4, for $\gamma>\hat{\gamma}(N)$, it is difficult to find a closed-form for the optimum size of the large CU both with and without Article XXIV. However, by studying the variations of the derivative of welfare of the large $\mathrm{CU}$ with respect to its size (see the online Appendix), we are able to determine an upper bound for the size of the large CU with Article XXIV: $k_{u c}^{o p t}<\frac{8}{9} N$ for $N \geq 9$; and a lower bound for the size of the large CU without Article XXIV: $k_{u u}^{\text {opt }}>\frac{8}{9} N+1$ for $N \geq 139$. This shows that, for $N \geq 139$ and $\gamma>\hat{\gamma}(N)$, the CU structure with Article XXIV is strictly more symmetric. 


\section{References}

Aghion, P., Antràs, P., Helpman, E., 2007. Negotiating free trade. Journal of International Economics 73, 1-30.

Bagwell, K., Staiger, R.W., 1998. Will preferential arrangements undermine the multilateral trading system? Economic Journal 108, 1162-1182.

Bagwell, K., Staiger, R.W., 1999. An economic theory of GATT. American Economic Review 89, 215-248.

Bagwell, K., Staiger, R.W., 2002. The Economics of the World Trading System. The MIT Press, Cambridge, Massachusetts.

Baldwin, R.E., 1996. A domino theory of regionalism, in: Baldwin, R.E., Haaparanta, P.J., Kiander, J. (Eds.), Expanding the Membership of the EU. Cambridge University Press, Cambridge.

Baldwin, R.E., 2006. Multilateralising regionalism: Spaghetti bowls as building blocs on the path to global free trade. World Economy 29, 1451-1518.

Bhagwati, J., 1993. Regionalism and multilateralism: An overview, in: De Melo, J., Panagariya, A. (Eds.), New Dimensions in Regional Integration. CEPR, London. Reprinted in Bhagwati, J., Krishna, P. and Panagariya, A. (eds.) 1999, Trading Blocks.

Bhagwati, J., 2008. Termites in the Trading System: How Preferential Agreements Undermine Free Trade. Oxford University Press, USA.

Bhagwati, J., Greenaway, D., Panagariya, A., 1998. Trading preferentially: Theory and policy. Economic Journal 108, 1128-1148.

Bloch, F., 1996. Sequential formation of coalitions with fixed payoff division and externalities. Games and Economic Behavior 14, 90-123.

Bond, E., Riezman, R., Syropoulos, C., 2004. A strategic and welfare theoretic analysis of free trade areas. Journal of International Economics 64, 1-27.

Bond, E., Syropoulos, C., 1996. The size of trading blocs, market power and world welfare effects. Journal of International Economics 40, 411-437.

Dinopoulos, E., Syropoulos, C., 2008. Multi-country tariff wars and the feasibility of free trade agreements. Typescript.

Ethier, W.J., 1998. Regionalism in a multilateral world. Journal of Political Economy 106, 1214-1245. 
Freund, C., Ornelas, E., 2010. Regional trade agreements. Annual Review of Economics 2, 139-166.

Goto, J., Hamada, K., 1999. Regional economic integration and article xxiv of the gatt. Review of International Economics 7, 555-570.

Grossman, G.M., Helpman, E., 1995. The politics of free-trade agreements. American Economic Review 85, 667-690.

Irwin, D.A., Mavroidis, P.C., Sykes, A.O., 2008. The genesis of the GATT. Cambridge University Press, New York, Princeton, New Jersey.

Krishna, P., 1998. Regionalism and multilateralism: A political economy approach. Quarterly Journal of Economics 113, 227-251.

Krugman, P., 1991. Is bilateralism bad?, in: Helpman, E., Razin, J. (Eds.), International Trade and Trade Policy. MIT Press, Cambridge, MA.

Maggi, G., Rodriguez-Clare, A., 1998. The value of trade agreements in the presence of political pressures. Journal of Political Economy 106, 574-601.

McMillan, J., 1993. Does regional integration foster open trade? Economic theory and GATT's Article XXIV, in: Anderson, K., Blackhurst, R. (Eds.), Regional Integration and the Global Trading System. Harvester Wheatsheaf, Hemel Hempstead.

Mrázová, M., 2010. Ohyama-kemp-wan customs union formation under imperfect competition: The wto article xxiv revisited. London School of Economics Typescript. Available at http://www.monikamrazova.com/KempWan.pdf.

Oladi, R., Beladi, H., 2008. Is regionalism viable? a case for global free trade. Review of International Economics 16, 293-300.

Ornelas, E., 2005a. Endogenous free trade agreements and the multilateral trading system. Journal of International Economics 67, 471-497.

Ornelas, E., 2005b. Trade creating free trade areas and the undermining of multilateralism. European Economic Review 49, 1717-1735.

Riezman, R., 1999. Can bilateral trade agreements help induce free trade? Canadian Journal of Economics 32, 751-766.

Saggi, K., Woodland, A., Yildiz, H., 2010. On the relationship between preferential and multilateral trade liberalization: The case of customs unions. SCID Working Paper 424.

Seidmann, D.J., 2009. Preferential trading arrangements as strategic positioning. Journal of International Economics 79, 143-159. 
Snape, R., 1993. History and economics of GATT's Article XXIV, in: Anderson, K., Blackhurst, R. (Eds.), Regional Integration and the Global Trading System. Harvester Wheatsheaf, Hemel Hempstead.

Syropoulos, C., 1999. Customs unions and comparative advantage. Oxford Economic Papers 51, 239-266.

Viner, J., 1950. The Customs Union Issue. Carnegie Endowment for International Peace, New York.

Yi, S.S., 1996. Endogenous formation of customs unions under imperfect competition: Open regionalism is good. Journal of International Economics 41, 153-177. 